معوقات توظيف الإنترنت يِّ تدريس الدراسات الاجتماعية بسلطنة عمان من وجهة نظر المعلمين

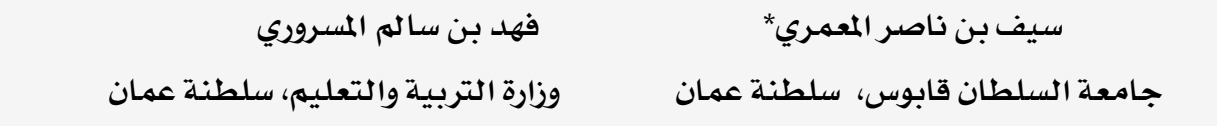

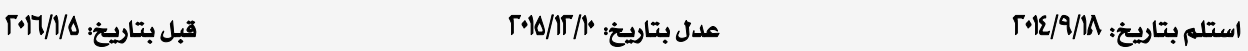

ملخص: هدفت هذه الدر اسة إلى تحديد المعوقات التي تواجه معلهي الدراسات الاجتماعية في توظيف الإنترنت في تدريس

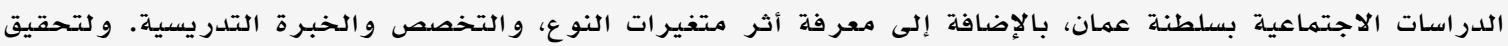

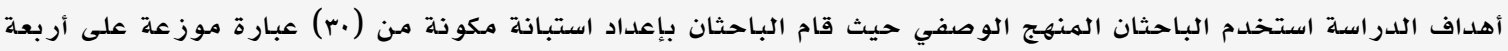

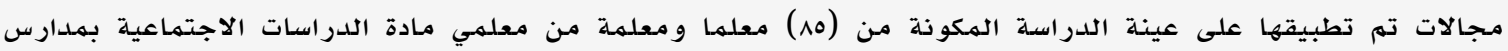

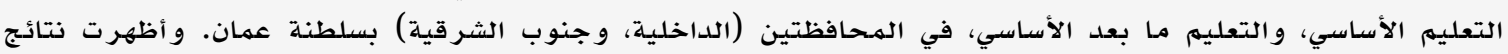

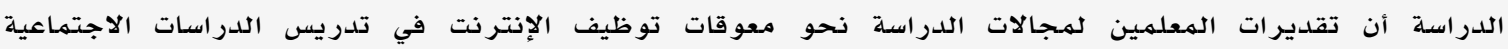

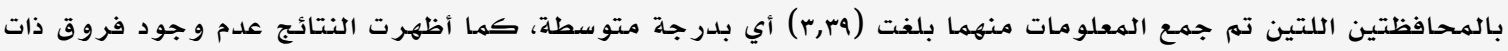

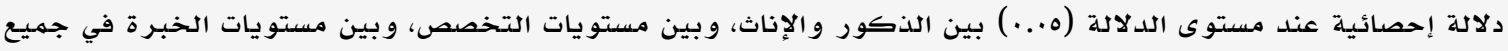

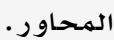

كلمات مفتاحية: الدر اسات الاجتماعية و الإنتر نت، التكنو لوجيا والتدريس، معوقات تدريس الدر اسات الاجتماعية.

\title{
The Barriers of Employing the Internet in Teaching Social Studies in the Sultanate of Oman from the Viewpoint of Teachers
}

\author{
Saif N. Al Mamari*, \\ \& Fahad S. Al Masrouri \\ Sultan Qaboos University, Sultanate of Oman Ministry Of Education, Sultanate of Oman
}

\begin{abstract}
This study aimed to reveal the barriers of employing the internet in teaching social studies in the Sultanate of Oman from the viewpoint of a sample of teachers. In addition, the study attempted to examine the effect of a set of variables including, gender, specialization and teaching experience. To achieve objectives of study the researchers prepared a questionnaire that consisted of 30 items that measure four components. The instrument was administered to a sample of 85 social studies teachers from basic education and post-basic education schools in governorates of Al-Sharqia South and Al-Dakaliah. The result of the study showed that degree of barriers of employing the internet in teaching social studies was moderate with a mean score of 3.39. In addition, the results also indicated no statistically significant differences (p. < 0.05) due to gender, specialization and experience in how they evaluate the barriers of employing internet in teaching social studies in all components.
\end{abstract}

Keywords: Social studies and internet, technology and teaching, social studies' teachers, barriers of teaching social studies.

*saifn@squ.edu.om 


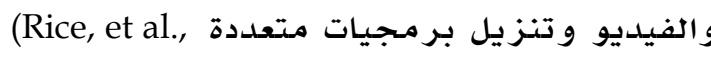
(1999 كما أنها تساعد على تعزيز الاستقصاء والإبداع من خلال إدماج أنواع متعددة من الاعن الاعناء

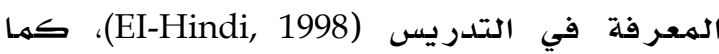

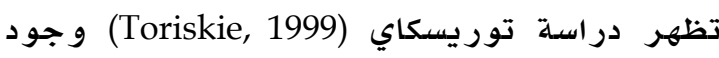
أثر إيجابي لاستخدام الإنترنت على تحصيل

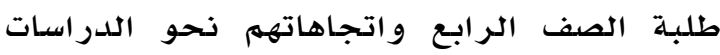

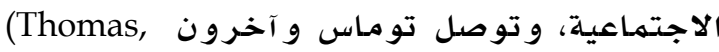

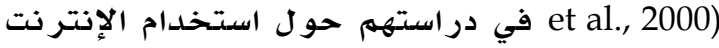

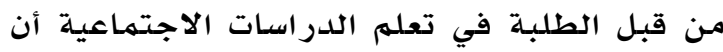

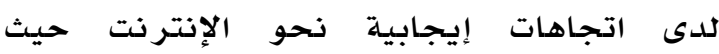
ينظرون إليها على أنها أداة مهمة لاكتهاب الاكتساب

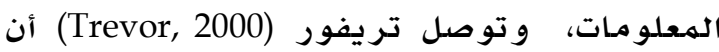

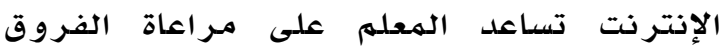

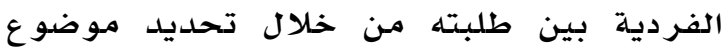

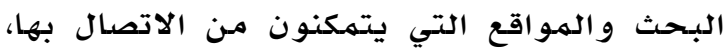

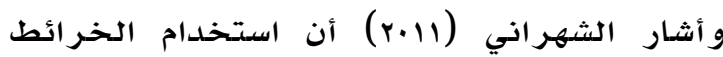

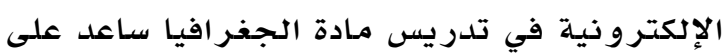
رفع التحصيل المعرفي للطلاب، وتوصل التبل الفار

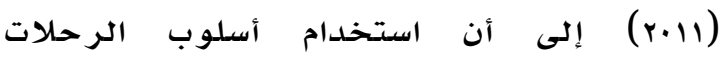

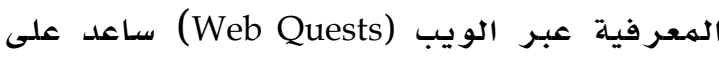
تنهية القدرة على التفكير التأملي في الجغرافيا. ومن منطلق أهمية دمج تكنولوجيا الاتصالات في

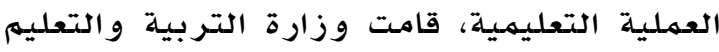

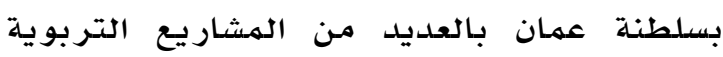

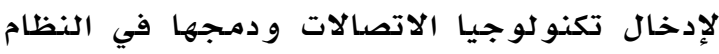
التربوي، فقد تم إدخال الحاسوب في الفصول الاتصل

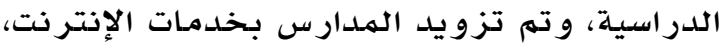
وكذلك تم تفعيل استخدام البوابة التعليمية، ولم يقتصر الأمر على توفير الأجهزة المادية بل المالِ

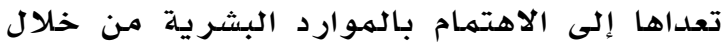

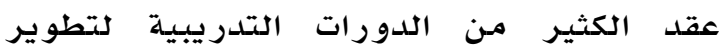

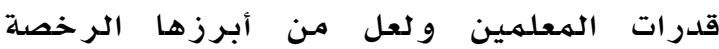

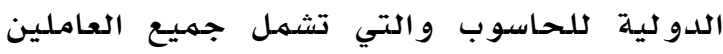

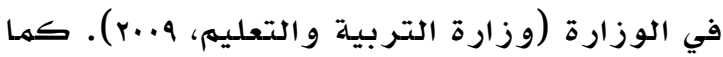

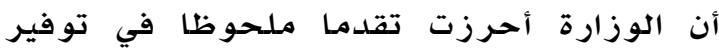

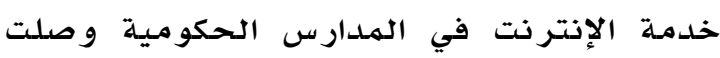

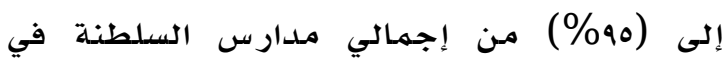

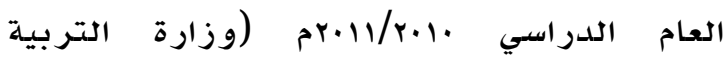

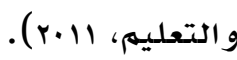

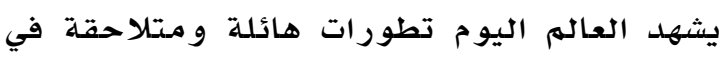

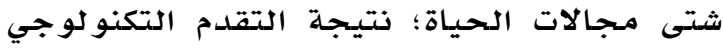

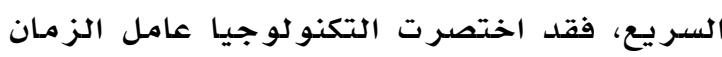

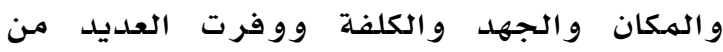

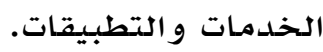

واهتمت النظم التربوية بتكنولوجيا المعلومات

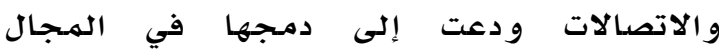

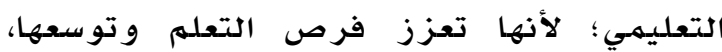
وتحسن من النتائج التعليمية، وتحقق المساواة

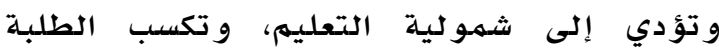

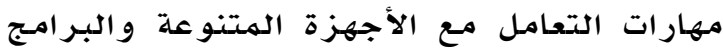

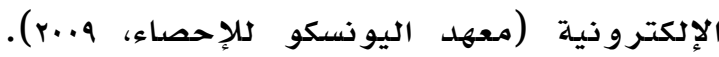

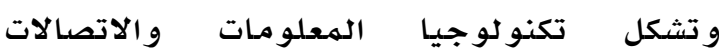
مجموعة متنوعة من المصادر والأدوات التي والاتيات تستخدم في إنشاء ونقل ونشر ونتون وتخزين و وإدارة

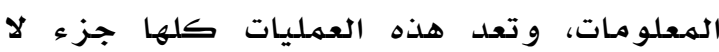

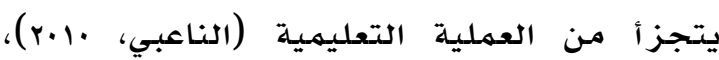

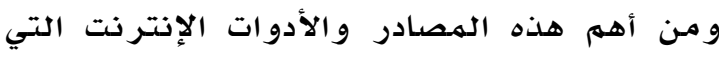
لها العديد من المميزات في العمدماتية العمدية التعليمية

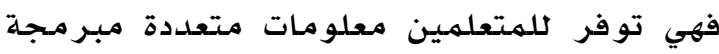

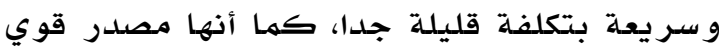

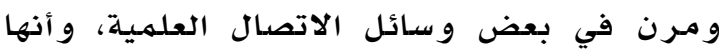

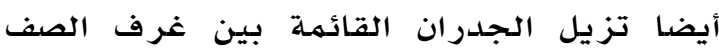

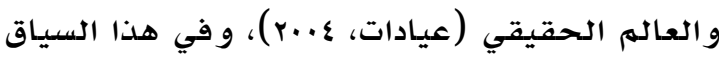

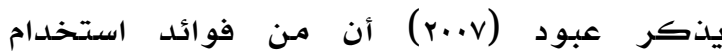

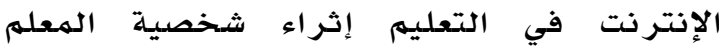

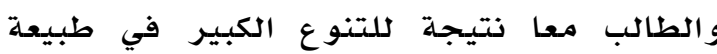

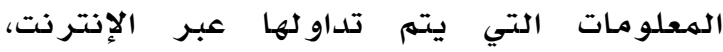
ولتعزيز فرص التعلم مدى الحياة، وللتقريب الانترني

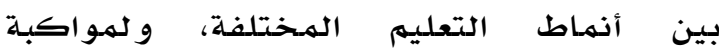
التطور ات الحديثة في العالم. وتعد الإنترنت أحد أهم الأساليب الحديثة التي

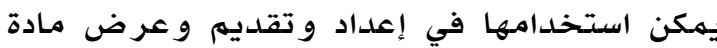

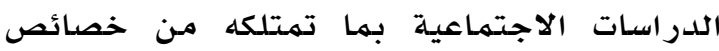
ومميزات تجعلها قادرة على تحقيق العديد من العناتيه

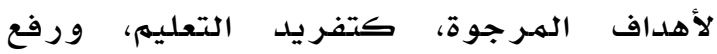
المستوى التحصيلي للطلبة، و تعزيز قدرة الطلبة الطبة

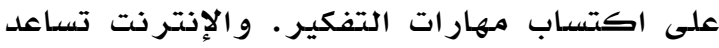
الطلبة على تكوين مجموعات نقاش على الشبكة، وتقدم عدد كبير من المصادر مثل الصور 
وفسرت العديد من النظريات معوقات توظيف

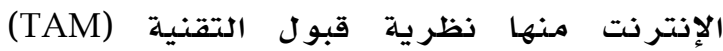
Technology Acceptance Modei بتطوير ها ديفس (Davis, 1989) و التي تحاول تفسر كيف يتهم قبول التقنيات الجديدة، وهي بشكلها المبسط تزعم أن الاستخدام التقنية الجديدة يمكن تفسيره من خلال قياس أو معر فة اله عاملين هما: سهولة الاستخدام الهتوقعـة لهذه

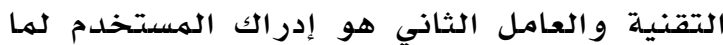
تقدمـه هذه التقنيلة من فائدة، واللذان بلدورهما

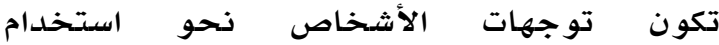

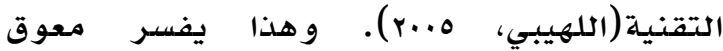
الاتجاهات السلبية و عدم الدافعية نحو استخدام

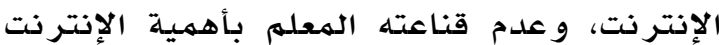
في العملية التدرريسية. و النظرية الأخرى نظرية الثقة بالنفس وصاحب هذه النظرية باندورا (Bandura,1986)، و محور هذه النظرية هو أن مستوى فاعلية الشخص

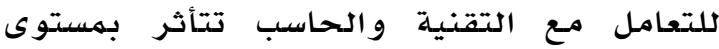
ثقته بنفسه للقيام بهذه المهارات و ليس الههارة

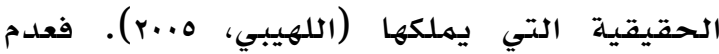

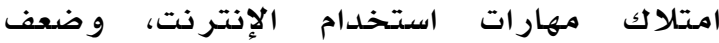

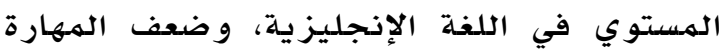

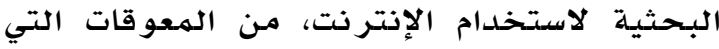
تؤثر بلدورها على اتجاه الأثخاص نحو تقبل الأل التقنية الجديدة.

ولقد أجريت العديد من الدراسات والبحوث التربوية في مجال معوقات توظيف الإنترنت في التدريس المهواد الدراسية بشكل عام، منها دراسـة

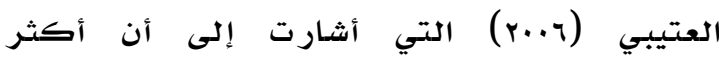
المعوقات الخاصة بالمعلم هي كثرة الأعباء

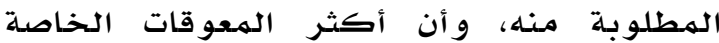

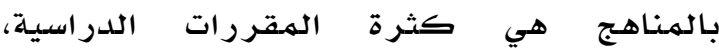
وبالنسبة للمعوقات الإدارية فكانت كثرة عدد الطلبة في الصف الواحد، بينهما كشفت دراسلة خز اعلة و جوارنه (Khazaleh \& Jawarneh, 2006)،

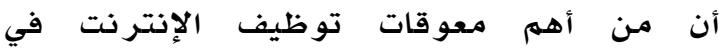
التدريس هي النقص الحاد في أجهزة الحاسوب و التجهيزات المتصلة بتكنولوجيا المعلومات في المري

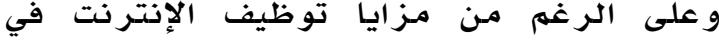
التدريس، إلا أن هناك فجوة مـا مئ بين الجهود

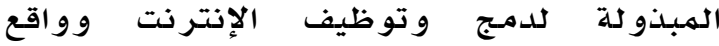
المـمارسة في الحقل التربوي، وهذا مـا أظهرته

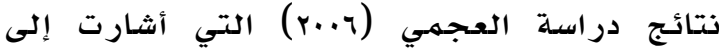
ضعف مهارات استتخدام الحاسوب في التدريس،

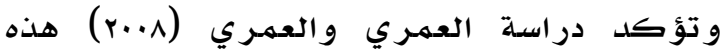

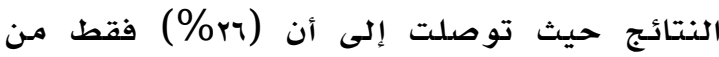

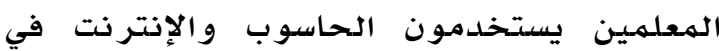

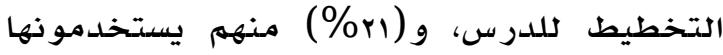

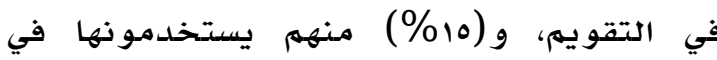

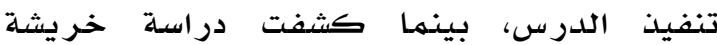

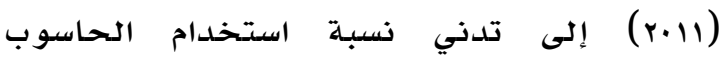

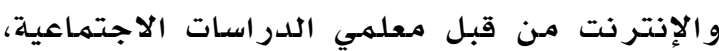

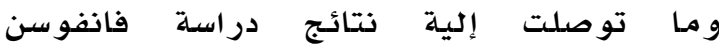
(VanFossen, 2001)

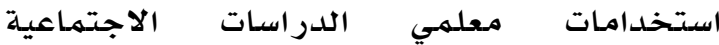

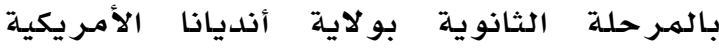

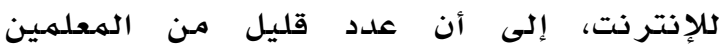

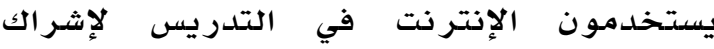
طلبتهم في أنشطة التعلمم التي تتطلب التفكير المعقد، على الرغم من امتلالك المعلمين لقدرة

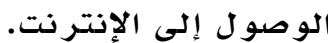

و تعتبر هذه النتائج انعكاسا لوجود معوقات

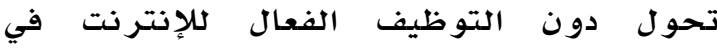
التدريس، ومن أهمر هذه الهعوقات كها يذكر ها لئ

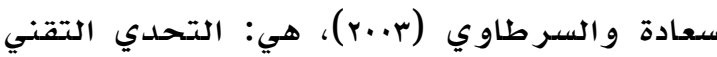

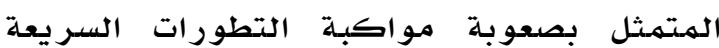
المتعلقة بهذه التكنولوجيا بالإضدافة إلى ضعف

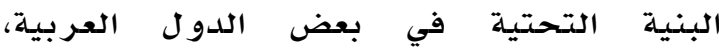
و اتجاهات المعلمين السلبيـة نحو الإنتر نت كأداة تعليهية تعلمية، وخلو الإنترنت من الرقابة التي

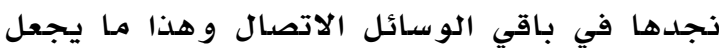
الإنتر نت سلاحا ذوا حدين لأنه قد يعر ض الطلبة إلى مخاطر تطغى على مـا نرجوه من الإنتر نت

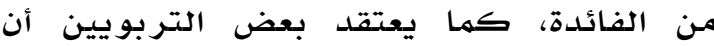
الكتاب هو محور العملية التعليمية وأن استخدام

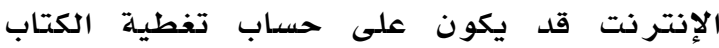
المقرر، و ظهور الفيروسات على شبكة الإنتر نت و التي قد تعمل على إتلاف بعض الملفات المهمهة. 


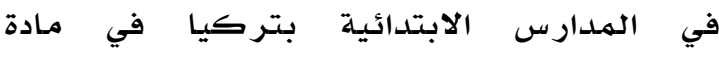

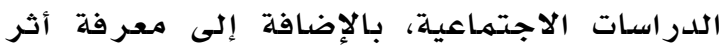

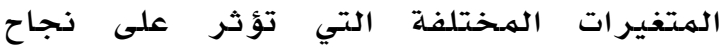

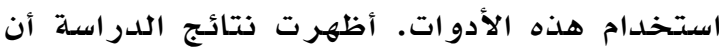
أكثر المعوقات التي تواجه استخدام تكنو لوجيا

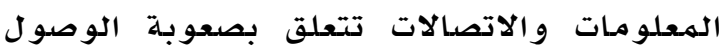
إلى أدوات تكنولوجيا الهعلومات و والاتصالات، وانعدام فرص التدريب أثناء الخدمة الخداء و أما دراسـة الحارثي (r|r.r) فهدفت إلى التعرف على معوقات استخدام الحاسوب في تدريس

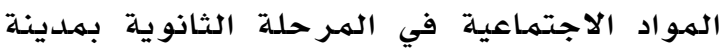

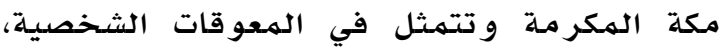
و الفنية، والإدارية، و التعرف على أبرز الآليات المقترحة للتغلب على تلك الهعوقات من وجههة نظر المعلمين المختصين في مدارس البنين، وبينت نتائج الدراسة أن معوقات استخدام الحاسوب في تلدريس المواد الاجتماعية في

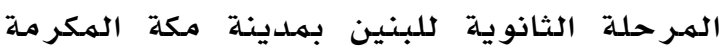
كانت بلدرجة كبيرة حيث كان المتوسط العام

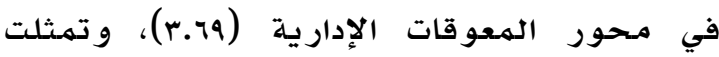
أبرز هذه المعوقات التي تخص هذا المحورر في

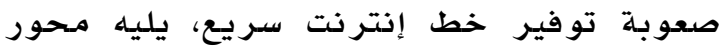

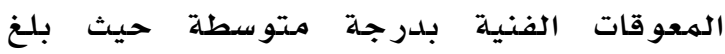

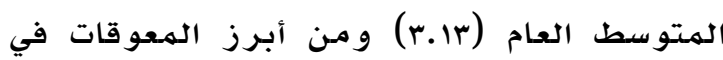

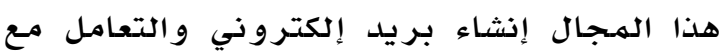

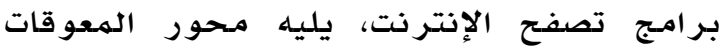

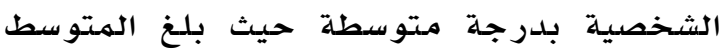

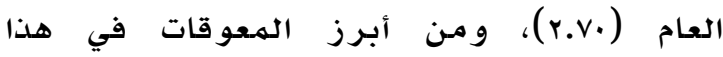

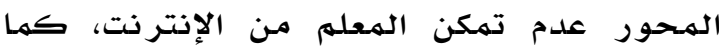

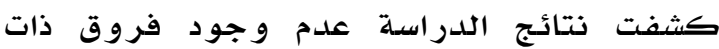

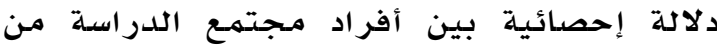

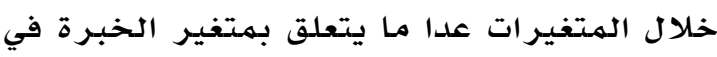
التدريس في مجال المعوقات الإدارية فإنه توجد لهدير فروق ذات دلالة إحصائية لصالح الذين لديهم خبرة في التدريس من (.1- 10 سنة ).

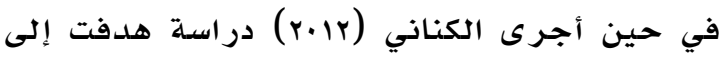

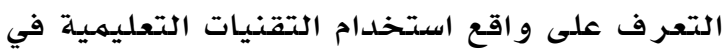
تدريس المواد الاجتهماعية بالهمرحلة المتوسطة

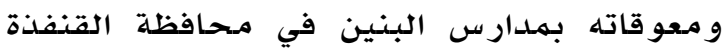
بالهـملكة العربية السعودية، وكشفت نتائج
المدارس، وقلة امتلاك طلبة المدارس لمهارات وكفايات تكنولوجيا المعلومات الأساسية، وقللة توافر البرمجيات التعليميـة ذات النوعية الجيدة

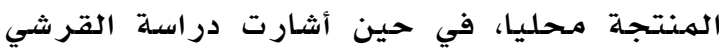
(r..v)

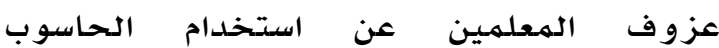

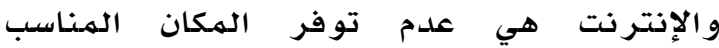

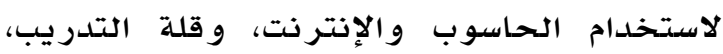
و ضعف اللغلة الانجليزية، و أظهر ت در اسلة العمري

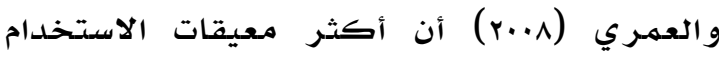

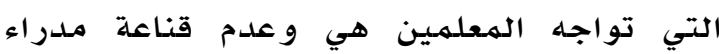
المدارس بالتغيير، وعدم مـلائمة البيئة الصفية

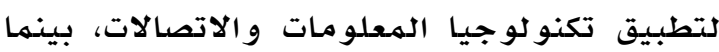

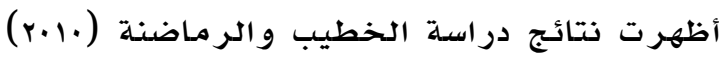

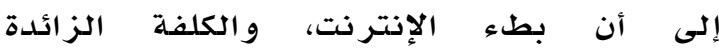
لاستخدامها خارج الهمدرسلة من أهم العوائق التي تحول دون استخدام المعلمين والطلبة لها في

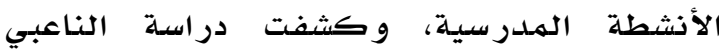

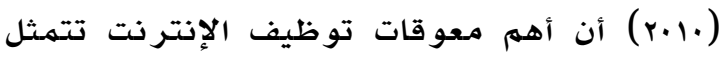

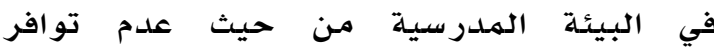
التجهيزات والبنى التحتية اللازمهة، وبعضها

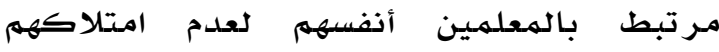
المهار ات الضرورية.

أما فيما يختص بمعوقات توظيف الإنترنت في

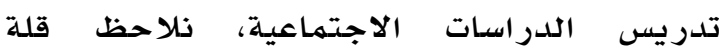

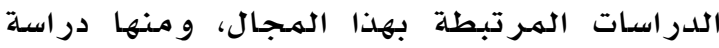

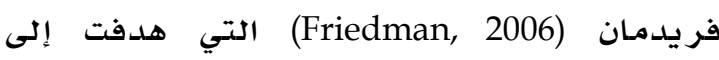
الكشف عن كيفية استخدام الهصادر الأولية

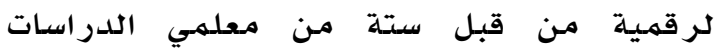
الاجتماعية بالهـر حلة الثانوية في و لاية فير جينيا الأمـريكية، أنه على الرغم مـن أنه هؤلاء الهمعلمين أظهروا اتجاه إيجابي نحو توظيف الهيف الهصادر الرقمية إلا أن استخدامها يعتمدل بلدرجة كبيرة الديرة

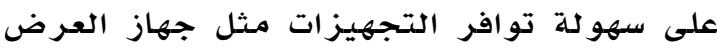

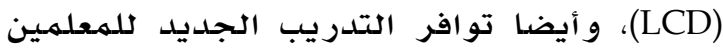
في كيفية تفعيل هذه مصدادر الإنترنت الرقمية

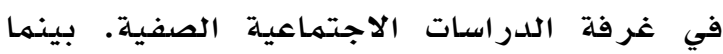

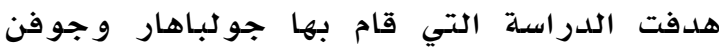
(Gulbahar and Guvan, 2008)

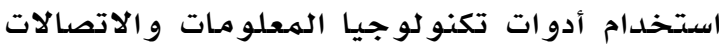




\section{مشكلة الدراسة و أسئلتها}

باكرغم من أن توظيف الإنترنت يساهم بشكل كبير في تحسين العملية التعليمية، ووفي زيادة

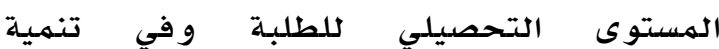
المستويات العليا في التفكير و في مر اعاة الفروق الفردية، وتكوين اتجاهات إيجابية نحو المادة، إلا

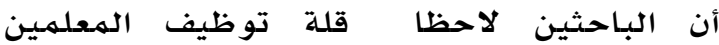

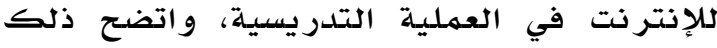
من خلال الزيارات الإثرافية التي قام

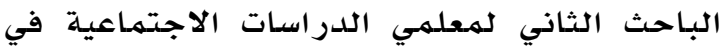

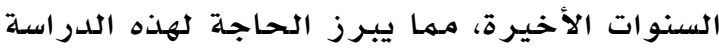
للكثف عن المعوقات التي تحد من توظيف

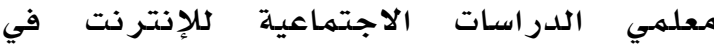
تلدريس المادة.

وفي ضوء ما سبق ظهرت الحاجة لإجراء هذه الدراسة التي تتلخص مشكلتها في الأسئلة الآتية: ا. ما تقديرات معلمي الدراسات الاجتماعية

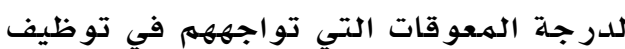

$$
\text { الإنتر نت في التدريس؟ }
$$

r. هل توجد فروق ذات دلالة إحصائية بين

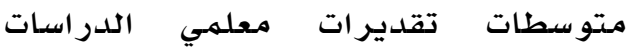
الاجتماعية لدرجـة المعوقات التي تواجههم

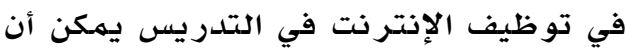

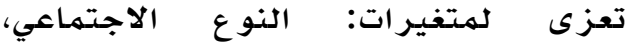

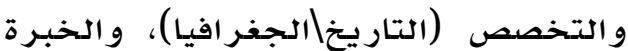

التدر يسيـية

أهداف الدراسة

$$
\text { تهدف هذه الدر اسـة إلى: }
$$

ا. تحديد درجة الهـعوقات التي تواجه معلهي الدراسات الاجتماعية في توظيف الإنتر نت الاهت

$$
\text { في التدرريس. }
$$

r. الكثف عن أثر متغيرات النوع، و التخصص، وسنوات الخبرة، على درجـة

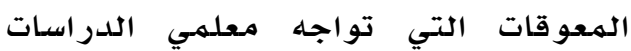

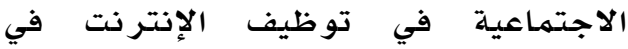

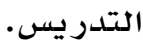

اللدراسة أن أكثر المعوقات التي تواجـه استخدام التقنيات التعليمية هي: ضعف الهينية البية التحتية للاتصالات وشبكة المعلومات، و عدم وجود بر امـج

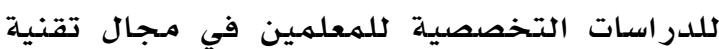
المعلومات و عدم وجود متخصصين و قلة الورش و المشاغل التربوية لتدريب الهعلمين على الهين المستجدات التقنية مـع قلة الدعم المادي، و عدم وجود فروق ذات دلالة إحصائية فيما يتعلق

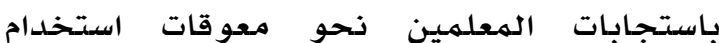
التقنيات الحديثة وفقات لهتغيري الدورات التدر يبية وسنوات الخبرة في التدريس.

ويتضح بعد استعر اض اللدراسات السـابقة أن البعض منها ركز على العوائق التي تحول دون

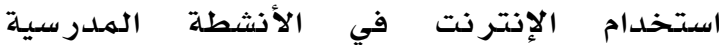

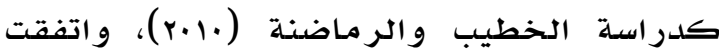
هذه الدراسلة مـع الدراسـات السـابقة في استخدام الاستبـانة كأداة لجمـع البيانات كدراسة النـاعبي

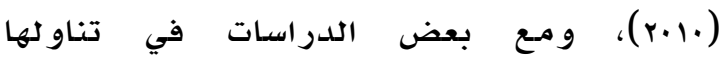

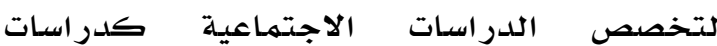
Gulbahar and Guvan, 2008; Toriskie, 1999; ) Thomas, et al., 2000; VanFossen, 2001;

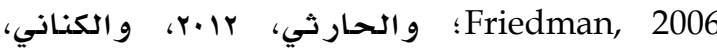

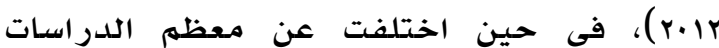
السابقة في حجم عينة الدراسـة، حيث بلغت عينة

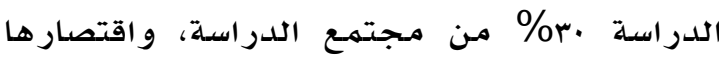

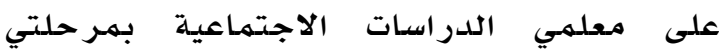
التعليهم الأساسي و التعليم ما بعد الأساسي، وفي مكان إجرائها حيث تعد الدراسة الأولى (بحلى الهدود

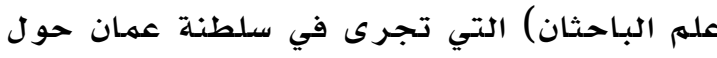
معوقات توظيف الإنتر نت في تدريس الدراسيات

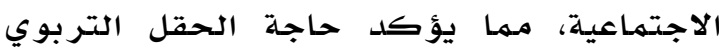
لإجراء هذه الدراسلة، للذلك جاءت هلذه الدراسلة

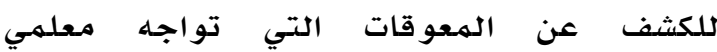
الدراسات الاجتماعية في توظيف الإنتر نت بسلطنة عمان.

كما تأتي هذه الدراسـة استجابة لتوصيات بعض

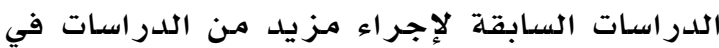
مجال معوقات توظيف الإنتر نت وفي تخصصات جديدة لهم يتم التطرق لها من قبل مبل (الناعبي،

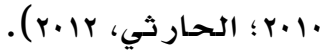


وتشهل أربعة مجاتلات الهعوقات

المتعلقة بالهعلم، والهعوقات المتعلقة

بالبنيـة التحتية والتجهيز الأساسية، و المعوقات المتعلقة بالطلبـة، و المعوقات الهتعلقة بالهنهج، و سيتتم قياس درجتها من خلال استبـانة تعد لغايات الدراسـة الحسالية تشتهل على مقياس ذي تدرج خماسي (كبير جدا، كبير، متوسط، قليل، ذيس

\section{بمعوق).}

r. معلمو الدراسـات الاجتهماعية: يقصد به

الهعلمون و الهعلمات يقومون الذين بتدريس مواد الاجدتهـاعية بهر حلة التعليهم الأساسي ومـرحلة التعليهم ما بعد بالأساسي في مـافظة الداخلية وومحافظة جنوب الشرقية في سلطنة عمان

\section{منهجية الدراسة و إجر اءاتها}

\section{منهج الدراسة}

لما كانت هذه الدراسة تهدف إلى تحديد

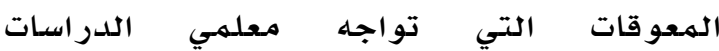
الاجتماعية في توظيف الإنتر نت في التدريس،

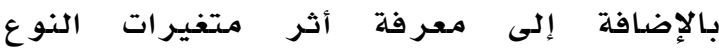

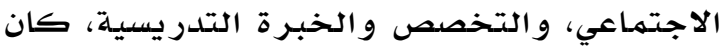
الهنهج الهستخدم هو الهنهج الوصفي المسحي، ويعد هذا المنهج من أكثر المناهـج مناسبـة لهذا النوع من الدراسات من وجهة نظر كثير من

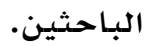

\section{مجتمع الدراسة وعينتها}

تألف مجتهـع الدراسة من جميع معلهي الدراسـات

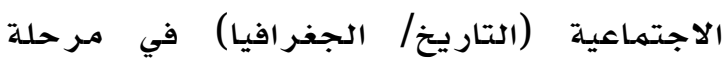

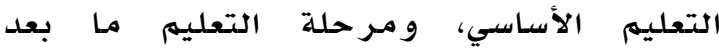

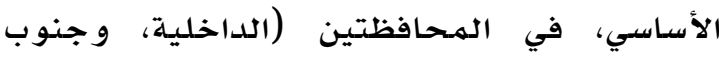

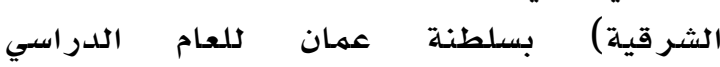

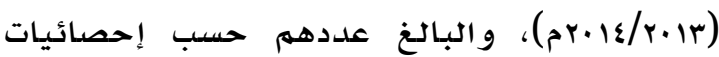

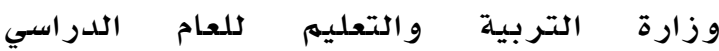

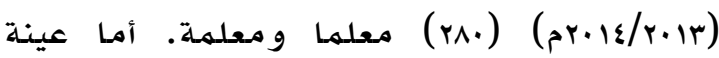

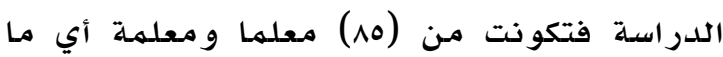

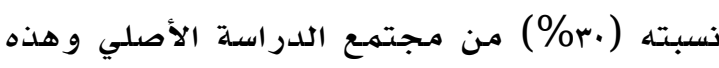

1. عـد هذه اللدراسة من الدراسات الأولى -

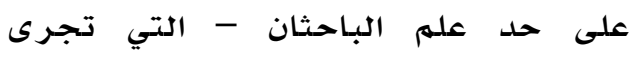
بسلطنة عمان لدراسة المعوقات التي التئي

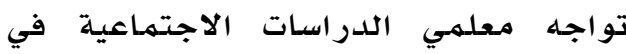

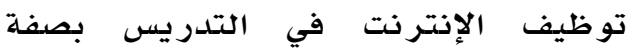
خاصة.

r. إثراء الأدب التربوي العماني وفتح المجال أمام دراسات جديدة تهتهم بالهمواضيع التكنو لوجية. r. قد يؤدى تحديد معوقات توظيف الإنترنت إلى إعطاء القائميـن على العملية التعليمية لهية

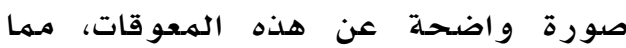

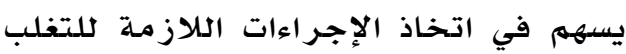
عليها. ع. المساعدة في معرفة ما يحتاجه المعلهم من تدريب ليتمكن من التغلب على المعوقات

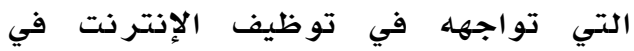

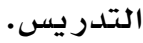
محددات الدراسة

ا. اقتصرت الدراسة على عينة من معلمي

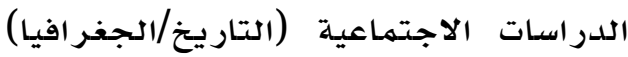

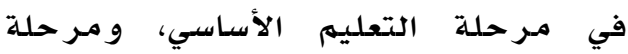

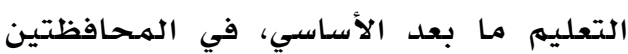
(الداخلية، وجنوب الشرقية) بسلطنة عمان r. تم تطبيق أداة الدرراسلة في العام

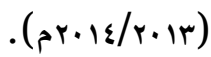

r. اقتصرت الدراسـة على الاستبـانة التي تكونت من أربعة مجالات، هي: الهعوقات الدرات

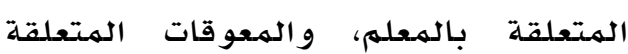
بالبنية التحتية والتجهيزات الأسـاسية،

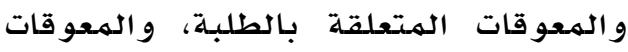
الهتعلقة بالمنهجر. مصطلحات الدراسة

ا. معوقات توظيف الإنتر نت: يعر فها الباحثان

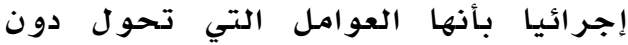

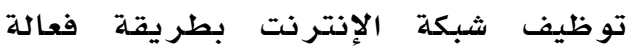


تم حذف (r) فقرات، و أصبـحت الاستبانة في

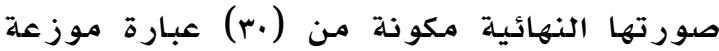
على أربعة مـجالات.

ثبات الأداة

للتأكد من ثبات الأداة، قام الباحثان بتوزيع الاستبانات على عينة استطلاعية بلغت (.r) معلما و معلمهة من خارج عينة الدراسـة، وتم حسـاب المابه معامل ثبات الأداة عن طريق معادلة ألفا مئه

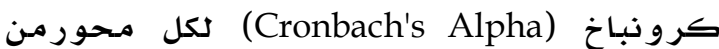
مـحاور الأداة، والمعامل الكلي كلأداة حيث كانت كلت كانت جميعها مـرتفعة، و هي كالتالي:

المعوقات المتعلقة بالمعلهم (.1 عبارات/

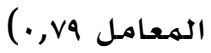

المعوقات المتعلقة بالبنية التحتية

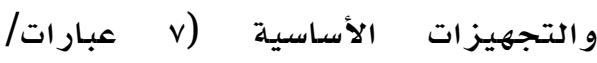

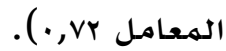

الهعوقات الهتعلقة بالطلبـة (7 عبارات/

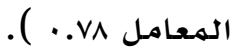

المعوقات المتعلقة بالمنهج (v عبارات/

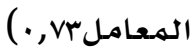

معامل الاتساق الكلي (•r عبارة/ الهـعامل $\cdot(\cdot, v \cdot$

\section{إجراءات التطبيق}

ا. عرض الاستبانة على مجموعة من ذوي الخبرة والاختصاص، في المناهج وطرق التدريس لتحكيمها.

تم تطبيق الاستبانة على عينة استطلاعية بلغ عددها

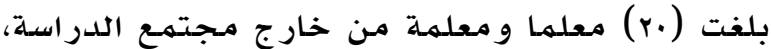

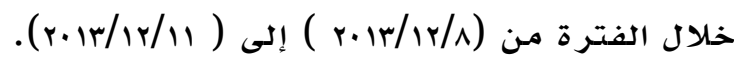
r. تم تطبيق الأداة بصورتها النهائية على أفراد عينة

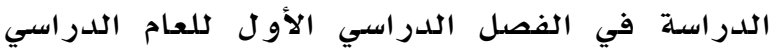
. (r) $r \varepsilon / r+1 r)$

ع. تفريغ البيانات وإدخالها في الحاسوب و وتحديد

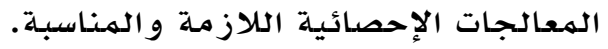

النسبة مقبولة، وتم اختيارهم بالطريقة

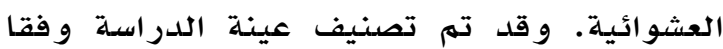

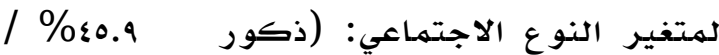

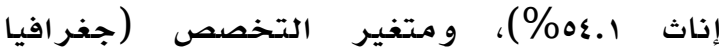

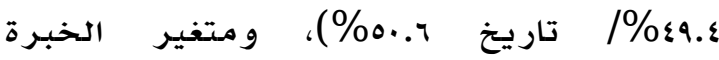

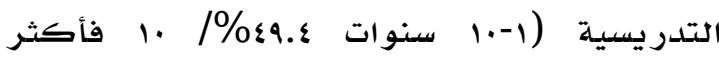

. (\%०..7

أداة الدراسة

بعد الإطلاع على الأدبيات والدراسات السابقة المتعلقة بمعوقات توظيف الإنتر نت في التدر يس؛

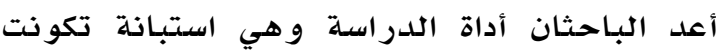
في شكلها النهائي من جزئين، هما:

الجزء الأول: يحتوي على بيانات عامـة، تتضهن معلومات عن أفر اد العينـة تلعلق بالنوع الإجتمهاعي و التخصص التدر يسي و الخبرة

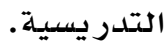

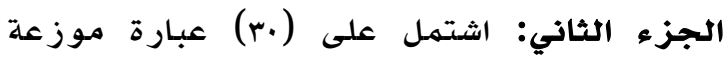

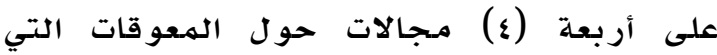
تواجه معلهي الدراسات الاجتماعية في توظيف الاتف الإنتر نت في التدريس وذلك كاجله التالي: الهعوقات

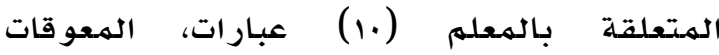
المتعلقة بالبنية التحتية والتجهيزات الأساسية

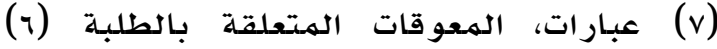

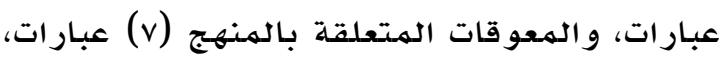
و يقابلها خمس استجابات وفق التدرج الخمهاسي (كبير جدا، كبير، متوسط، قليل، ليس معوق) ).

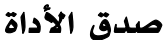
تم إستخراج الصدق الظاهري للاستبـانة عن طريق عرضها في صورتها الأولية، على عدد من

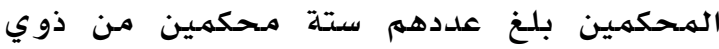

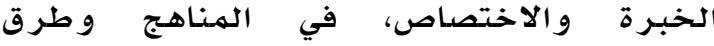
التدريس في جامعة السلطان قابوس، بالإضافة

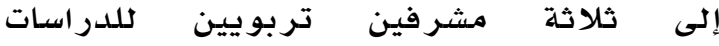
الاجتماعية، حيث أبلدى الأفاضل المحكمون

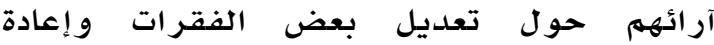
صياغتها اللغوية و إضافة بعض الفقرات الأخرى،

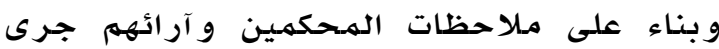
تعديل بعض الفقرات بالحذف أو الإضافة. وقد 
جدول أميار

المتوسطات الحسابية والانحرافات المعيارية والأهمية النسبية (الرتبة)

\begin{tabular}{|c|c|c|c|c|}
\hline \multicolumn{5}{|c|}{ لمجالات الدراسة } \\
\hline المعوق & الانحراف المعياري & الحسابي & المحور & \\
\hline كبيرة & $\cdot, \uparrow$ & $r, \wedge V$ & المعلوقات المتعلقة & $r$ \\
\hline كبيرة & צT, & $r, v r$ & بالمنهوجات المتعلقة & $\varepsilon$ \\
\hline كبيرة & •,Ar & $r, v r$ & البالبنية التحتية التوقات المتعلقة & r \\
\hline منوسطة & $\cdot$, OV & r,Tr & بالمعلم & 1 \\
\hline منوسطة & $\cdot, \leq 7$ & $r, r q$ & لعام للمجالات & \\
\hline
\end{tabular}

مجال "المعوقات المتعلقة بالهعلهم" في المرتبة

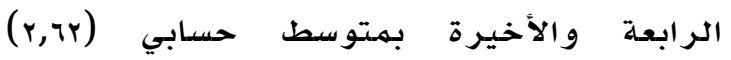
و بدرجة متوسطة بالنسبة لبقية المـجالات.

أمـا عما أظهرته نتائج الدراسـة حول كل مهجال

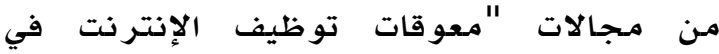

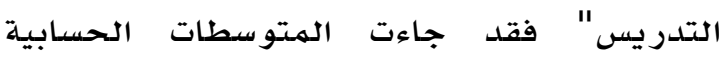

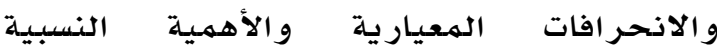

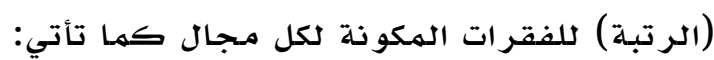

المجال الأول: المعوقات المتعلقة بالمعلم المتوسطات الحسابية والانحر افات المعيارية

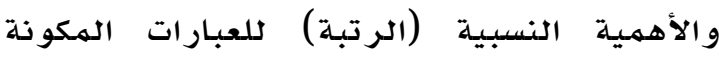
للمجـال الأول المعوقات المتعلقة بالمعلهم، ويبين جدو ل r ذ ذلك.

ويتبين من جدول r أن المعوقات المتعلقة

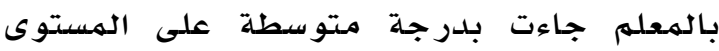

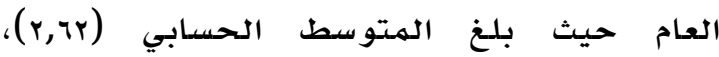
واحتلت بذلك الرتبة الرابعة والأخيرة بالنسبـة

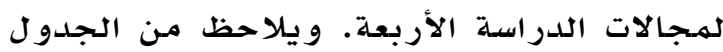
وجود معوق واحد بدرجة كبيرة وهو"كثرة

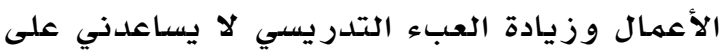

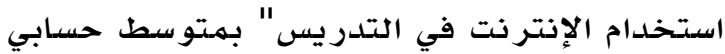

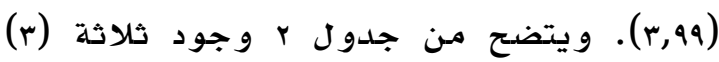

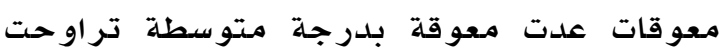

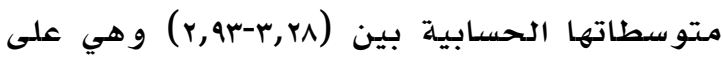
الترتيب: "لهم أتلق تلدريبا في أثناء الخدمـة في بي

\section{المعالجة الإحصائية}

لتحقيق أهداف الدراسـة استخدم البـاحثان رزمـة

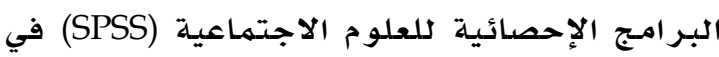
تحليل البيانات التي تم جمعها بعد تطبيق أداة

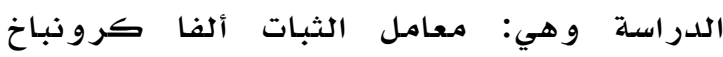

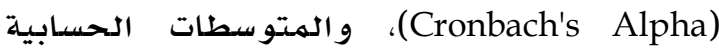

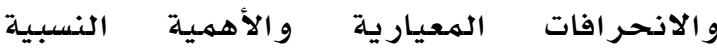

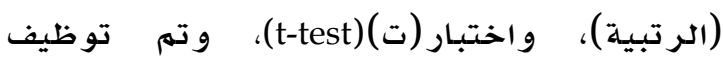

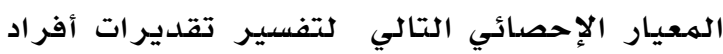

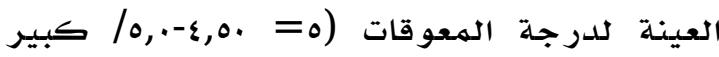
جدا؛ ع = .0, r

\section{نتائج الدراسة}

أولا: الإجابة عن السؤال الأول ونصه: ما

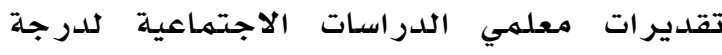
المعوقات التي تواجههم في توظيف الإنترنت في في

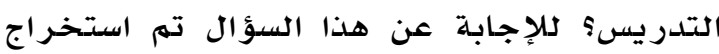

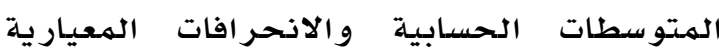
لجميع مجالات الدراسـة والمجال العام، ويبين

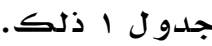

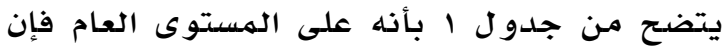

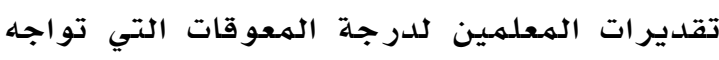
معلمـي الدراسـات الاجتماعية في توظيف الإنتر نت في التدريس جاءت بدرجة متوسطة في إجمالي

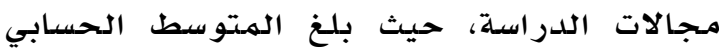

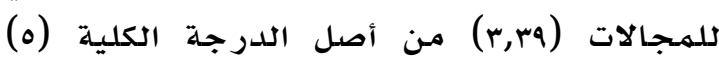
در جات.

أما المتوسطات الحسابية لكل مـجال من مـجالات الدراسة الهتعلقة بالمعوقات التي تواجـه معلهي

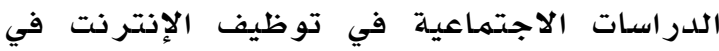

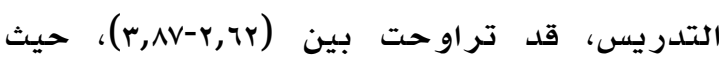

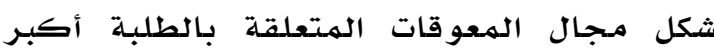

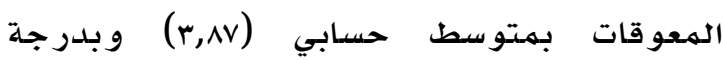

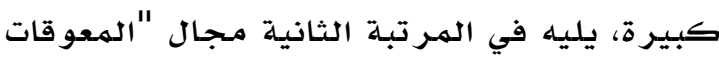

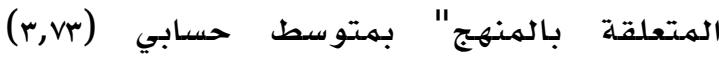

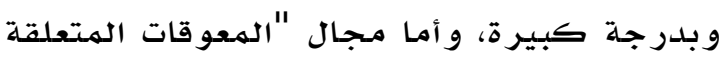

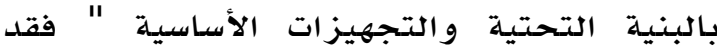

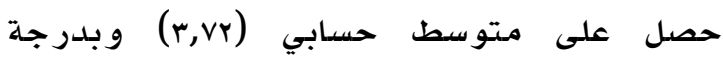
كبيرة و احتل بذلك المـرتبة الثالثة و وجاء 


$$
\begin{aligned}
& \text { يوجد لدى وقت كاف لتوظيف الإنتر نت في } \\
& \text { كيفية توظيف الإنتر نت في التدريس"، و "لا }
\end{aligned}
$$

\begin{tabular}{|c|c|c|c|c|}
\hline المعوق & الانحراف & الحسابي & 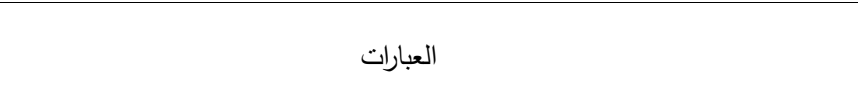 & م \\
\hline كبيرة & $1, \cdot 11$ & ५,११ & كثرة الأعمال وزيادة العبء التدريسي لا يساعدني على استخدام الإنترنت في التدريس. & 1 \\
\hline 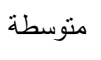 & $1, \varepsilon \vee V$ & $r, r \wedge$ & لم أتلق تدريبا في أثناء الخدمة حول كيفية نوظيف الإنترنت في التدريس. & r \\
\hline 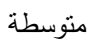 & 1,179 & $r, r v$ & لا يوجد لاي وقت كاف لتوظيف الإنترنت في التدريس. & r \\
\hline 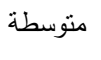 & 1, ror & r,qr & ضعف مستواي في اللغة الإنجليزية يشكل عقبة في استخدامي للإنترنت. & $\varepsilon$ \\
\hline قليلة & $1, r \circ 9$ & $r, £ q$ & عدم امتلاكي لمهارات استخدام الإنترنت. & 0 \\
\hline قليلة & $\cdot, 9 \cdot 1$ & r, rᄉ & عدم الثقة بصحة المعلومات المنشورة عبر الإنترنت. & 1 \\
\hline قليلة & $1,11 \mathrm{r}$ & r, ro & عدم قدرتي على تتظيم المعلومات التي يتم الحصول عليها من شبكة الإنترنت. & v \\
\hline قليلة & $\cdot, 99 \vee$ & $r, \cdot v$ & ضعف المهارة البحثية لدي لاستخدام الإنترنت. & $\wedge$ \\
\hline قليلة & $\cdot, 9 \vee r$ & 1,94 & لا توجد لدي الرغبة في استخدام الإنترنت في التدريس. & 9 \\
\hline قليلة & $\cdot, \wedge \circ \leqslant$ & $1, \times 4$ & عدم قناعتي بأهمية الإنترنت في العملية التدريسية. & 1. \\
\hline متوسطة & $\cdot, \mathrm{oV}$ & $r, T$ & المتوسط العام & \\
\hline
\end{tabular}

المتوسطات الحسابية والانحرافات المعيارية والأهمية النسبية (الرتبة) لمجال المعوقات المتعلقة بالمعلم

الإنتر نت"، و "قلة توافر مختبـر ات الحاسوب داخل

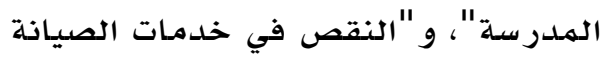

للأجهزة بصورة دورية"، و "سوء التجهيزات

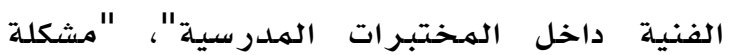

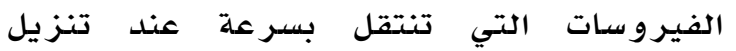

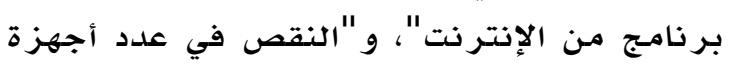
الحاسوب داخل المختبر ".

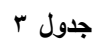

المتوسطات الحسابية والانحرافات المعيارية والأهمية النسبية (الرتبة) للمجال

\begin{tabular}{|c|c|c|c|c|}
\hline المعوق & المعياري & الحسابي & العبارات & 5 \\
\hline كبيرة & $\cdot, 911$ & L, & 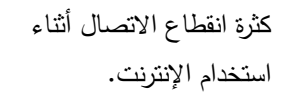 & 1 \\
\hline كبيرة & $1, \cdot v \varepsilon$ & $r, \wedge \Lambda$ & داخل المدرسة. & r \\
\hline كبيرة & $1,1 \leqslant$. & $r, \Lambda T$ & للأجهزة بصورة دورية. & r \\
\hline كبيرة & $1,1 \leqslant$. & $r, v r$ & المختبرات التجيزات الفنية داخل & $\varepsilon$ \\
\hline كبيرة & $1,1 \times 1$ & $r, \pi r$ & مشكلة الفيروسات التي تنتقل & 。 \\
\hline كبيرة & $1,|v|$ & $r, 70$ & الحاسوب داخل المختبر. & 7 \\
\hline متوسطة & $1, r \wedge q$ & $r, .$. & الراقوم التي تفرضها بعض اللدخول إليها. & v \\
\hline كبيرة & •,Aזی & $r, v r$ & المتوسط العام & \\
\hline
\end{tabular}
المعوقات المتعلقة بالبنية التحتية والتجهيزات الأساسية.
التدريس"، و "وضعف مستواي في اللغة

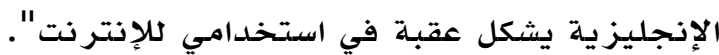
و يلاحظ من الجدو ل وجود معوقان بلدرجة قليلة

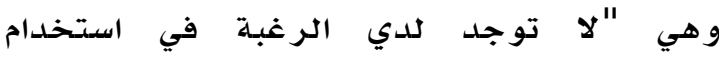
الإنتر نت في التدريس" بهتوسط حسابي (r, (1,)،

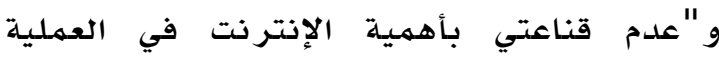
التدريسية" بمتوسط حسابي (1,V7).

المجال الثاني: المعوقات المتعلقة بالبنية التحتية والتجهيزات الأساسية الهية

الهتوسطات الحسـابية والانحر افات المعيارية

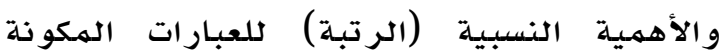

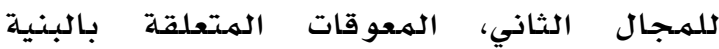

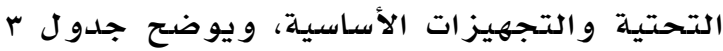
ذلك.

يتبين من جدول r أن المعوقات المتعلقة بالبنية

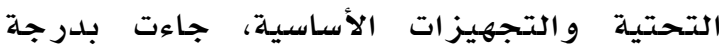
كبيرة على المستوى العام ، حيث بلغ المتوسط

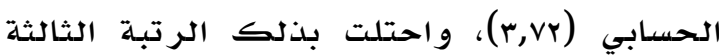
بالنسبة لمجالات الدراسة الأربعة. ويتضح من الجدول السـابق وجود (7) معوقات عدت معوقة بدرجة كبيرة تراوحت متوسطاتها

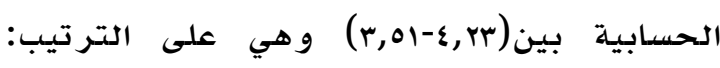

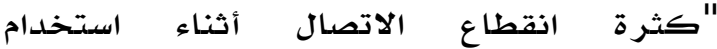


"صعوبة متابعة الطلبة بشكل فردي"، و "عدم

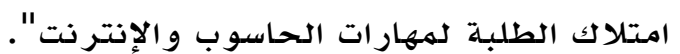
ويلاحظ من الجدول ع وجود معوق واحد

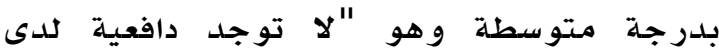

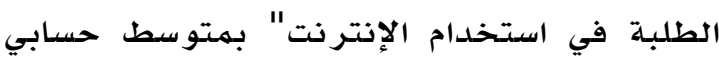
$\cdot(r, \wedge \Lambda)$

\section{المجال الرابع: المعوقات المتعلقة بالمنهج}

المتوسطات الحسابية والانحر افات المعيارية

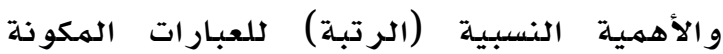

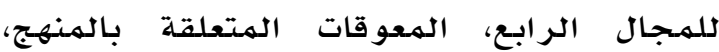
و يوضتح جلدول ه ذلك.

يتضح من جدول ه أن تقديرات أفراد العينة

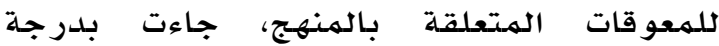
كبيرة على المستوى العام، حيث بلغ المتوسط الهـ

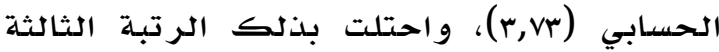

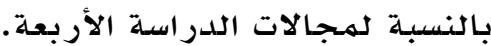
ويتبين من الجدول ه وجود خمسـة (0) معوقات بدرجة كبيرة تراوحت متوسطاتها الحسابية

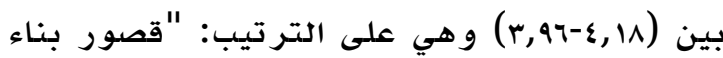

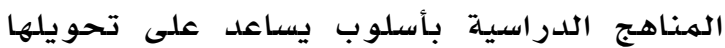

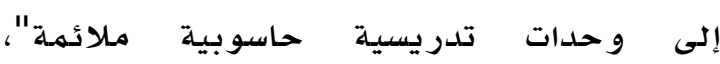

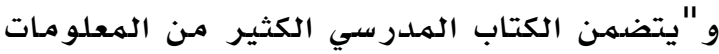
التي تتطلب الحفظ و تقف عائق أمام استخدام

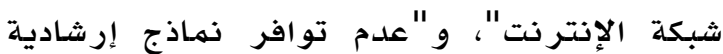
ضمن المنهج توضتح كيفية توظيف الإنترنت في الإنس

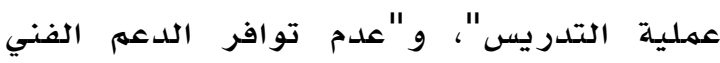

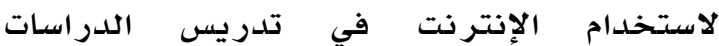

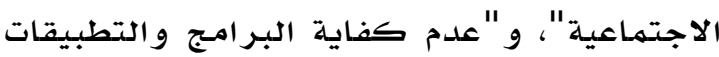

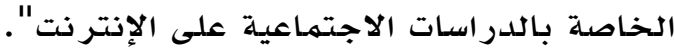
و يلاحظ من الجدول ه وجود معوقان بدرجة

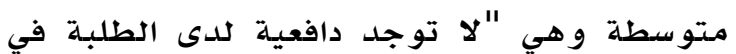

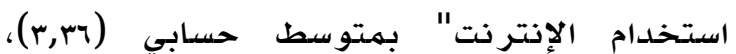

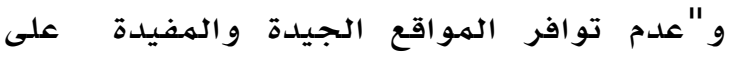

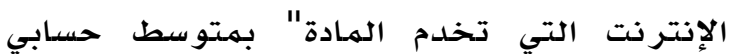

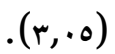

و يلاحظ من جلدول ب و جود معوق واحد بدرجة

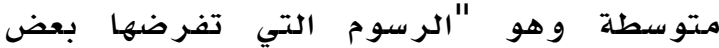

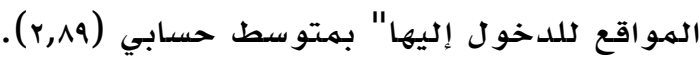

المجال الثالث: المعوقات المتعلقة بالطلبة

الهتوسطات الحسابية والانحر افات المعيارية

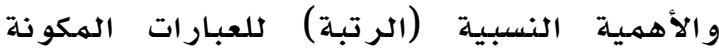

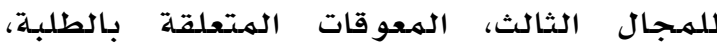
و يبين جدول \& ذلك.

جدول ؛

المتوسطات الحسابية والانحرافات المعيارية والأهمية النسبية (الرتبة) للمجال المعوقات المتعقة بالطلبة

\begin{tabular}{|c|c|c|c|c|}
\hline المعوق & المعياري & الحسابي & العبارات & م \\
\hline كبيرة & $\cdot, \lambda \cdot r$ & $\varepsilon, \Gamma q$ & 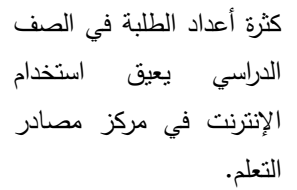 & 1 \\
\hline كبيرة & $\cdot, 9 \vee \wedge$ & $\varepsilon, \cdot \Lambda$ & موفا من الدخول إلى مواقع القعابة على & r \\
\hline كبيرة & $1, \ldots 9$ & $\varepsilon, \cdot V$ & 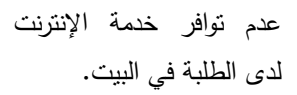 & r \\
\hline كبيرة & $\cdot, \wedge T \leqslant$ & $\{, .7$ & فردي. & $\varepsilon$ \\
\hline كبيرة & $1, \cdot v \cdot$ & $r, 7)$ & عدم امتلاك الطلبة لمهارات & 0 \\
\hline منت من & $1,1 \cdot v$ & $r, \cdot 1$ & في استخدام الإنترنت. لوافية الطلبة & 1 \\
\hline كبيرة & $\cdot, 7 \cdot 1$ & $r, \wedge V$ & المنوسط العام & \\
\hline
\end{tabular}

يتضح من جلدول ع أن المعوقات المتعلقة بالطلبـة، جاءت بلدرجة كبيرة من أجمالي محاور

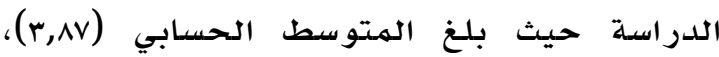

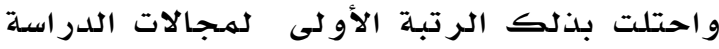
الأر بعـة. - احسل

ويتبين من الجدول السابق وجود خمسـة (0)

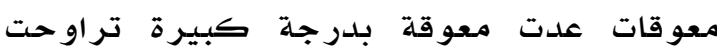

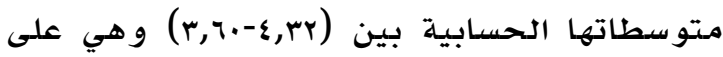

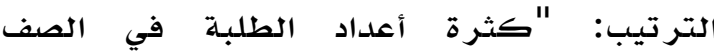
الدراسي يعيق استخدام الإنترنت في مركز

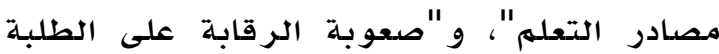

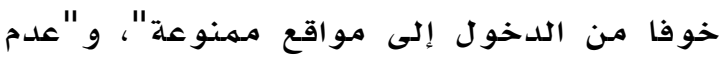

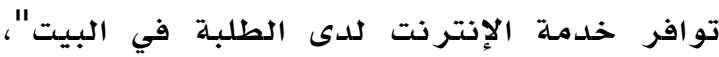




\section{- جدول}

المتوسطات الحسابية والانحرافات المعيارية والأهمية النسبية (الرتبة) للمجال المعوقات المتعلقة بالمنهج

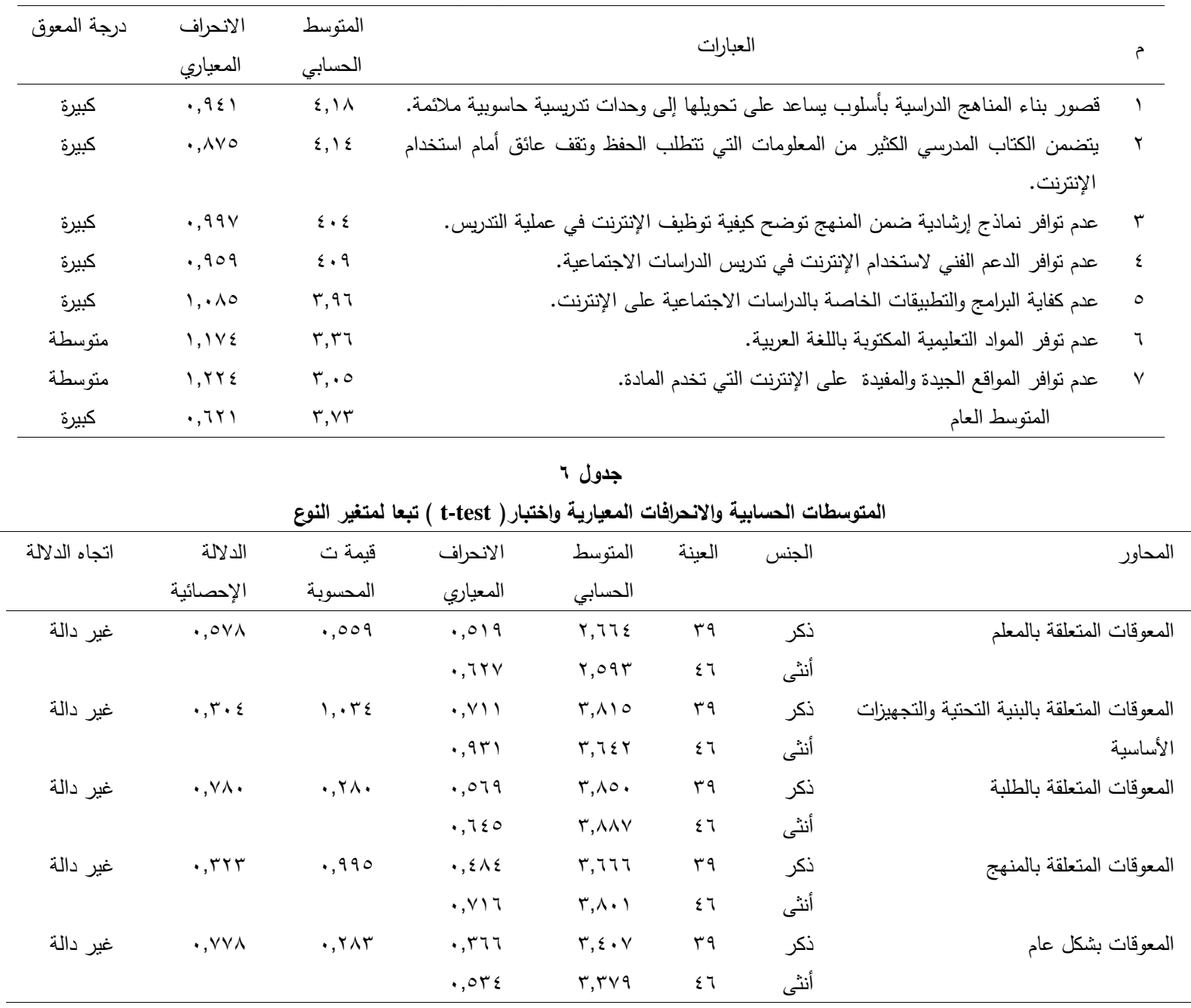

بين الذكور و الإناث في جميع المحاور.

ثانيا: متغير التخصص: للكشف عن أثر متغير التخصص تم استخدام المتوسطات الحسابية

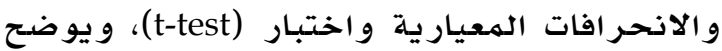

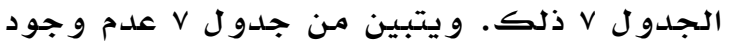

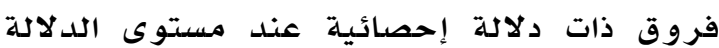

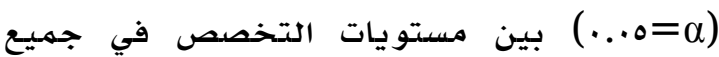
المحاور . المان. ثالثا: متغير الخبرة التدريسية: لكشف عن أثر متغير الخبرة التدريسية تم استخدام الهتوسطات

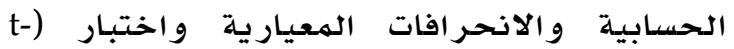
test

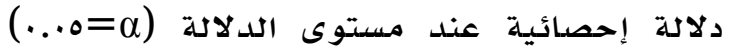
بين مستويات الخبرة التدريسية في جميـع المححاور.
ثانيا: الإجابة عن السؤال الثاني وونصه: هل توجد

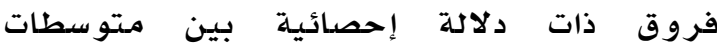

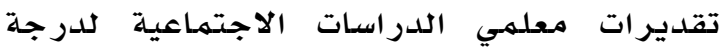

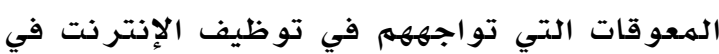

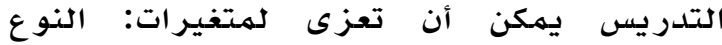

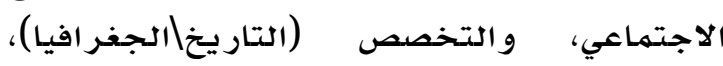
و الخبرة التدر يسية؟ واعية

للإجابة عن هذا السؤال تم استخدام اختبار(ت)

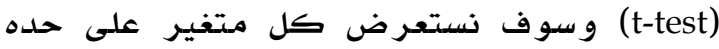

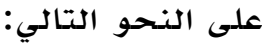

أولا: متغير النوع: للكشف عن أثر متغير النوع

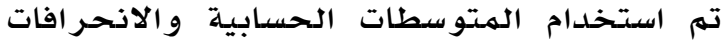

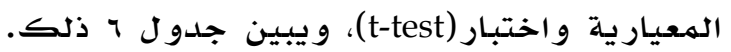
ويلاحظ من جدول 1 عدم وجود فروق ذات

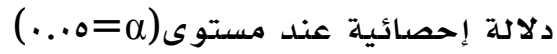


الجدول

المتوسطات الحسابية والانحرافات المعيارية واختبار (t-test ) تبعا لمتغير المرحلة الدراسية

\begin{tabular}{|c|c|c|c|c|c|c|c|}
\hline اتجاه الدلالة الدالة & الإحصائية & قالمسمة ت & الانحراف & الحسابي & 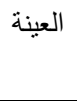 & التخصص & المحاور \\
\hline \multirow[t]{2}{*}{ 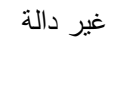 } & $\cdot, 000$ & $\cdot, 09 \pi$ & $\cdot, 00 r$ & $r, 011$ & $\varepsilon r$ & 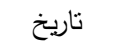 & المعوقات المتعلقة بالمعلم \\
\hline & & & $\cdot, 7 \cdot 0$ & r,Trr & $\varepsilon r$ & جغرافيا & \\
\hline غير دالة ل & $\cdot, 097$ & •,OHT & $\cdot, \wedge 79$ & $r, \uparrow$. & $\varepsilon r$ & تاريخ & المعوقات المتعلقة بالبنية التحتية \\
\hline غير دالة ل & & & 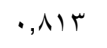 & r,vVv & $\varepsilon r$ & جغرافيا & والتجهيزات الأساسية \\
\hline غير دالة ل & $\cdot, 9 \times 1$ & $\cdot, \cdot+44$ & $\cdot, 0 \leq 7$ & $r, \Lambda \vee r$ & $\leq r$ & 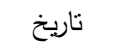 & المعوقات المتعلقة بالطلبة \\
\hline غير دالة ل & & & $\cdot, 779$ & $r, \wedge 4 \wedge$ & $\varepsilon r$ & جغرافيا & \\
\hline غير دالة الة & $\cdot, \varepsilon \leqslant 0$ & $\cdot, \vee \neg \vee$ & ( ) & r,TAv & $\leq r$ & ت ت تاريخ & المعوقات المتعلقة بالمنهج \\
\hline 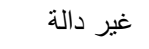 & & & $\cdot, 0 \wedge r$ & $r, v q$. & $\varepsilon r$ & جغرافيا & \\
\hline \multirow[t]{2}{*}{ غير دالة الة } & $\cdot, \varepsilon \wedge \varepsilon$ & $\cdot, v \cdot r$ & $\cdot, \leqslant \circ \mathrm{V}$ & r, rot & $\leqslant r$ & 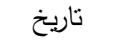 & المعوقات بشكل عام \\
\hline & & & $\cdot, \varepsilon \vee \cdot$ & $r, \varepsilon r v$ & $\varepsilon r$ & جغرافيا & \\
\hline
\end{tabular}

و أظهرت نتائج الدراسة أن أبرز الهعوقات

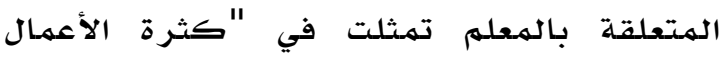
وزيادة العبء التدريسي لا يساعدني على

استخدام الإنتر نت في التدريس" حيث جاءت بلدرجة كبيرة، وقد يعزى ذلك إلى ارتفاع نصاب الهعلمين من الحصص الدرراسية وكثرة ولهرة الأعمال الكتابية الهطلوبة منهم وقيامهم بالعديد

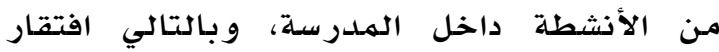

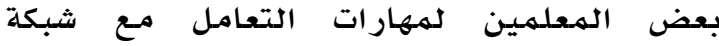
الإنترنت، وتؤكد هذه النتيجة ما توصلت إليه

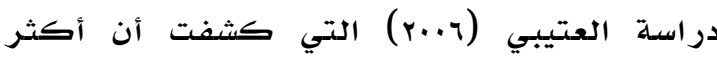

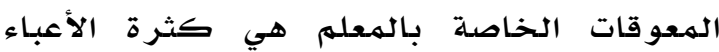

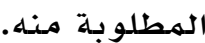

و تعتبر "لا توجد لدي الرغبة في استخدام الإنترنت في التدريس"، و و"عدم قناعتي بأهمية

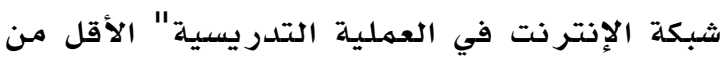
حيث المتوسطات في هذا المجال و قد تعزى هذه الإه النتيجة إلى رغبـة المعلمين في تطوير أساليب

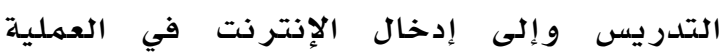
التعليميلة، كما أن انتشار أجهزة الحهاسوب في إدهي

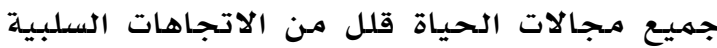
عند المعلمين نحو استخدام الإنترنت، و تأتي هذهاه النتيجة مختلفة مـع النتيجهة التي توصلت إليها

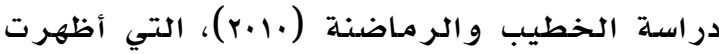

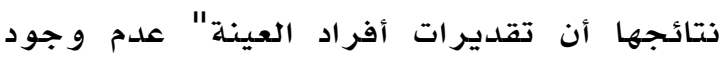

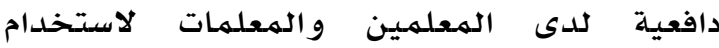

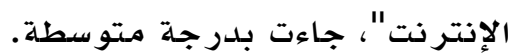

\section{مناقشة نتائج البحث}

كشفت نتائج الدراسـة أن تقديرات أفراد عينة

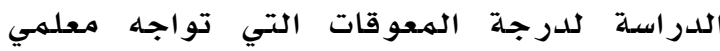

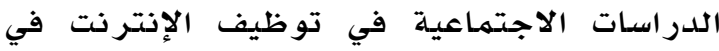

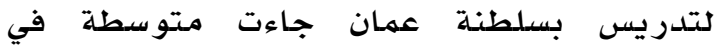
إجمالي مجالات الدراسـة، الأمـر الذي يدعم أهماءلهيلة أهمية هذه الدراسـة في معرفة مـا يحتاجه المعلهم مـن

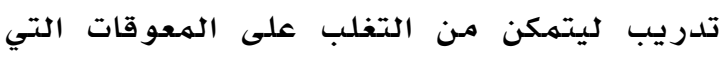
تواجهه في توظيف الإنترنت في التدريس و في

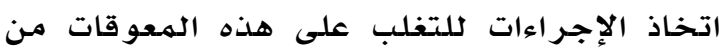

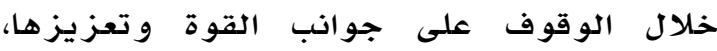
و تشخيص جوانب الضعف والعمل على التخلص منها و علاجها، و لا تعكس هذه الذه النتيجة الجهود المبلذولة من قبل النظام التعليهي في سلطنة وهنة عمان، والمتمثل في قيام وزارة التربية و التعليه بعقد الكثير من الدورات التدريبية لتطوير قدرات الهعلمين في مسجال التكنو لوجيا و لعل من الن

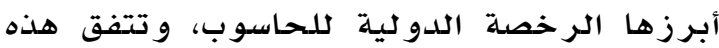

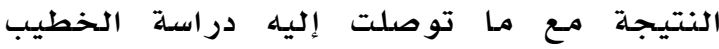

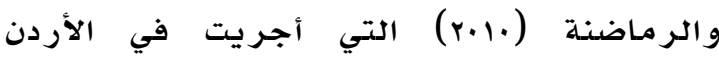

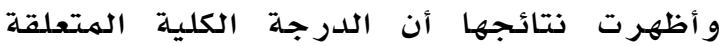

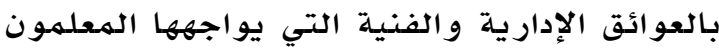

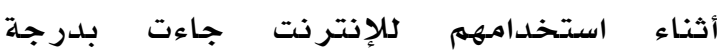

$$
\text { متو سطة. }
$$


يحد من سرعة إدماج الوسائط التكنولوجية في العملية التربوية.

وأظهرت نتائج الدراسلة أن أبرز المعوقات

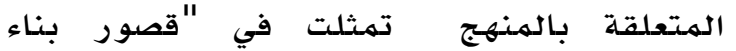
المناهـج الدراسية بأسلوب بسلو بهاعد على تحويلها

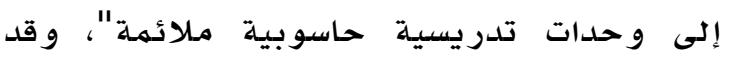
يعزى ذلك إلى تضمن الكتاب المدرسي الكثير من المعلومات التي تتطلب الحفظ فقط. و جاءت

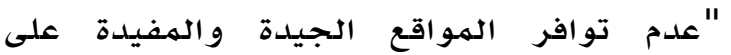

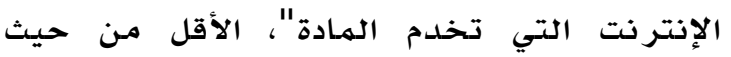

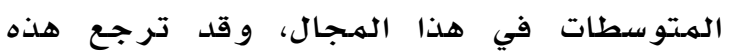

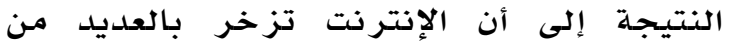
الهواقع الجيدة التي تخدم الهـادة الدراسية. وأظهرت نتائج الدراسلة أنه لا توجد فروق ذات

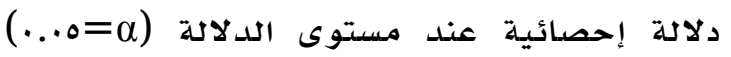
بين الذكور والإناث في جميع المجـالات، و يبـرر ذلك إلى أن كل من الجنسين يواجهون هذه المعوقات بنفس الدرجة، مهما يشير إلى التشابه إنه الكبير بين بيئة مدارس الذكور وبيئة مدارس الذس الذانس

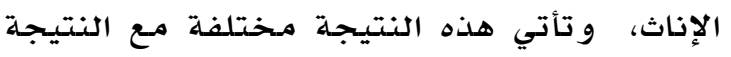

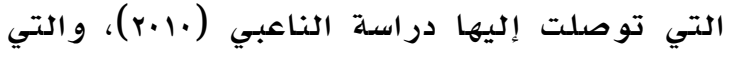

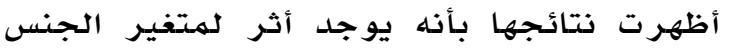

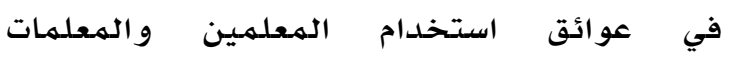

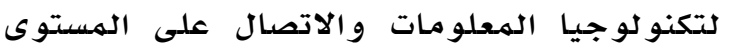
الشخصي و التدريس لصالح الذكور .

كما كشفت نتائج الدراسة عدم وجود فروق ذات دلالة إحصائية بين مستويات التخصص في جميع المجالات، ويفسر الباحثان ذلك بتهيه بتشابه الدورات التدريبية التي يخضع لها يها معلمو

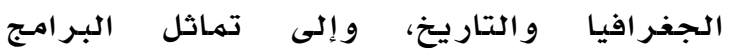

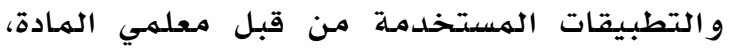

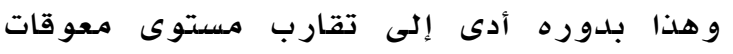

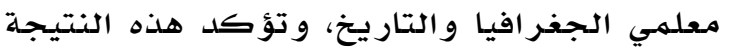

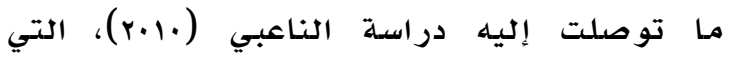

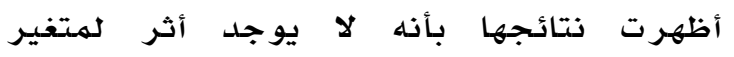

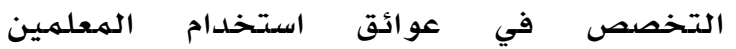

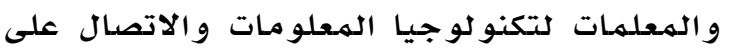
المستوى الشخصي و التدريس.
وكشفت نتائج الدراسة أن أبرز الهعوقات

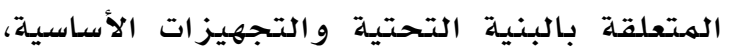
تمثلت في "كثرة انقطاع الاتصال أثناء استخدام

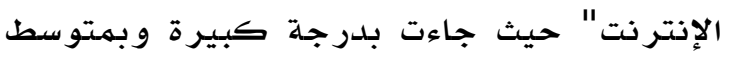

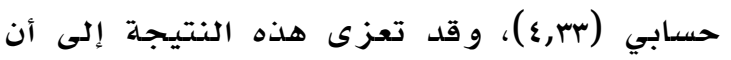

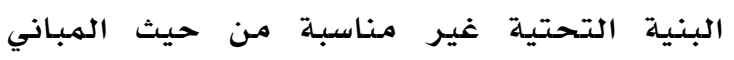

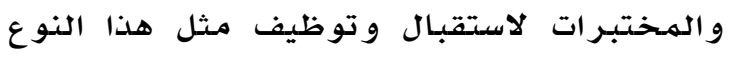
من التدريس مها يؤدى إلى كثرة انقطاع

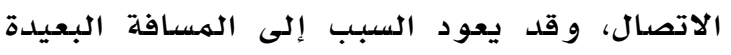

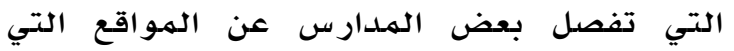
يتوفر فيها اتصال جيد بالشبكة الرئيسية. بينها كانت أدنى استجابة لأفر اد العينة في هذا

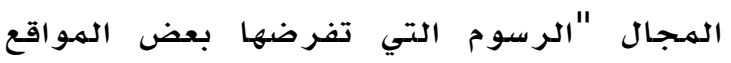
للدخول إليها"، و لعل سبب ذلك الكول يعود إلى قلة الرسوم المفروضدة، و أن بعض الموقع توفر فترة

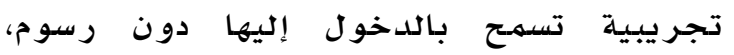
وتؤكد هذه النتيجة متفقة مـا توصلت إليه

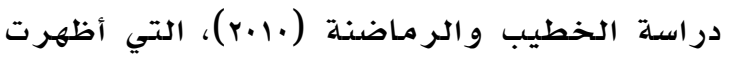

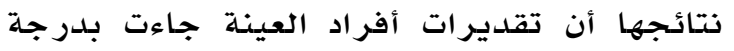

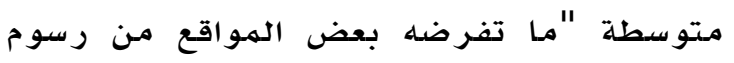

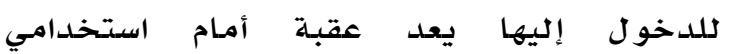

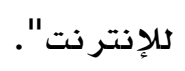

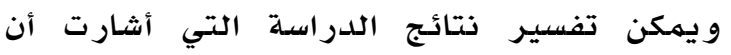

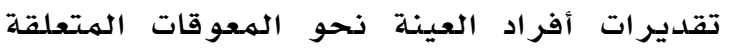

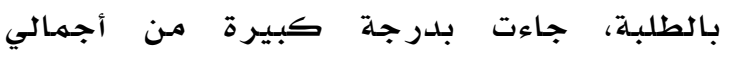

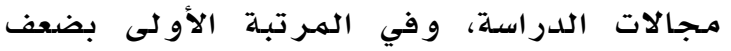
مهارات الطلبة في كيفية الاستفادة مـن مصادر

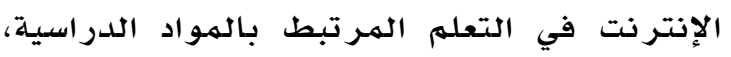

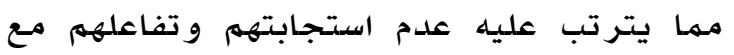
هذا الأسلوب الجديد في التدريس. و يرجع الباحثان الاستجابة الكبيرة "كثرة أعداد

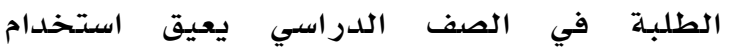

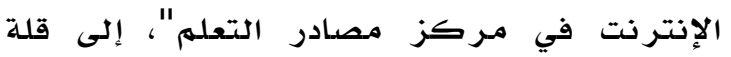

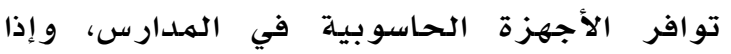
توافرت فإنها لا تتناسب مـع الأعداد المتزايلدة من الهن

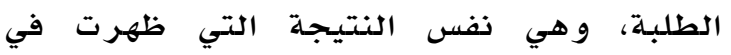

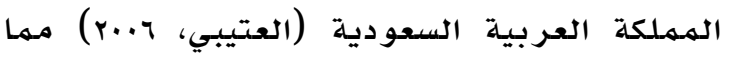
يشير تشابه أوضاع الأنظمة التربوية في منطقة

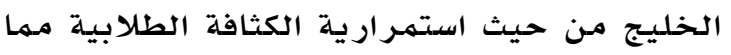


7. إجراء دراسات مهاثلة للدراسـة الحالية لتشمل محافظات تعليمية مختلفة وراء ورلى مر احل تعليمية أخرى.

V. إجر اء دراسـة لهعر فة الاحتياجات التدريبية

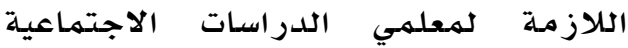
لاستخدام و توظيف الإنتر نت في التدريس.

$$
\text { المر اجع }
$$

\section{References}

الحارثي، عبدالله بن عيضه (r.r). معوقات استخدام الحاسب الآلي في تدريس الهمواد الاجتماعية في المرحلة الثانوية للبنين

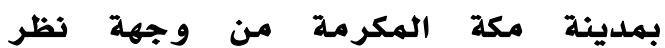
المعلمين المختصين في مدارس البنين.

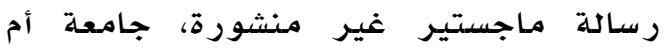
القرى، المـملكة العربية السعودية.

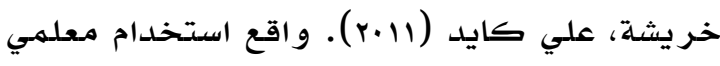
الدراسات الاجتهاعية في الأردن للحاسوب

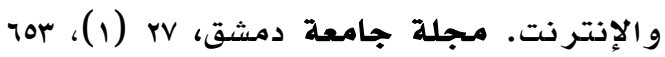
$.79 .-$

الخطيب، لطفي محمدـ؛ و الرمضانية، معاذ خالد

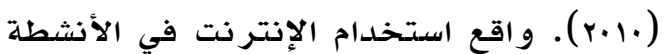

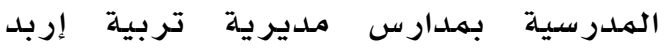

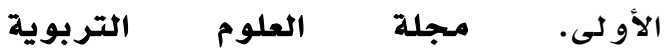
والنفسية،11| (ع)، 19V - 190. سعادة، جودت أحمد؛ و السرطاوي، عادل فايز

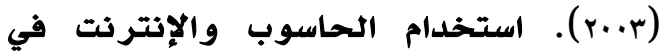
ميادين التربية والتعليه. عمان، الأردن: دار الشروق للنشر و التوزيع.

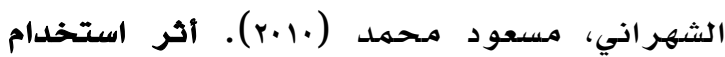
الخرائط الإلكترونية من من ملادل الشبكة العنكبوتية في تلدريس مادة الجغرافيا على تحصيل طلاب الصف الثاني المتوسط بمحافظة بيشة واتجاهاتهم نحوها. رسالة دكتوراه غير منشورة، جامعة أم القرى،

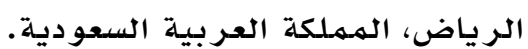
عبود، حارث (r...v). الحاسوب في التعليم. عمان، الأردن: دار و ائل للنشر .
و أظهرت نتائج الدراسـة أنه لا توجد فروق ذات

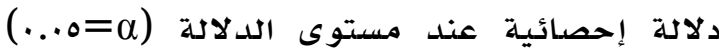
بين مستويات الخبرة التدريسية في جميع المهجالات، ويبرر ذلك إلى أن أفراد العينة مهما

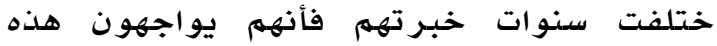

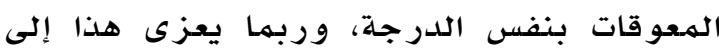
قلة الدورات التدريبية الهـخصصة لتكنو لوجيا

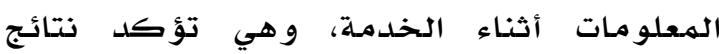

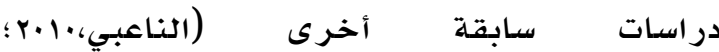

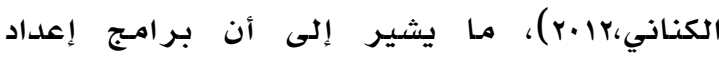

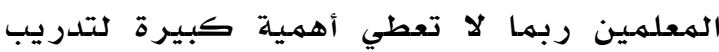
المعلمين المتتخرجين حديثا على كيفية توظيف

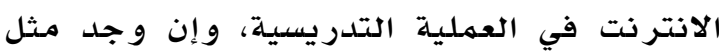
هذه الاهتمام ربهما توصلت الدراسـة إلى نتائج مشابهة إلى النتائج التي توصلت إليها دراسلة

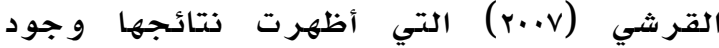
فروق ذات دلالة إحصدائية في معوقات استخدام الإنتر نت في التدريس لصالح متقدمي الخبرة. توصيات ومقترحات الدراسة في ضوء نتائج الدراسة الحالية يوصي البـاحثان بمها يلي:

1. العمل على تحسين وتحديث الإنتر نت وزيادة سرعتها، والاهتمام بالبنية التحتية

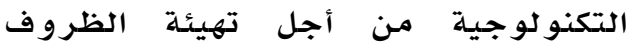
المناسبة للمعلمين في توظيف الإنتر نت. r. عقد دورات تلدريبية للطلبة بحيث يتم

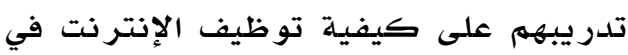

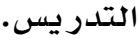

r. ضرورة تطوير الهناهج لمواكبة التغيرات

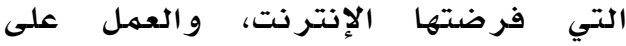

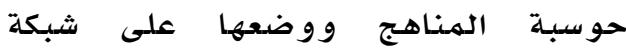

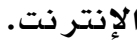

ع. العمل على التقليل مـ الأعباء الدراسية

على المعلى لزيادة تفاعلهم مـع هذا النهط الهـ من التعليهم و إقبالهم عليه. ه. من خلال نتائج الدراسة يقترح الباحثان إجر اء بحوث حول الموضو عات التالية: 
معهد اليونسكو لإحصاء (بq.....). دليل لقياس

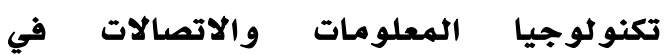

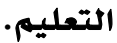

http://www.uis.unesco.org/Library/Doc uments/ICTguide11_Tec2_AR.pdf

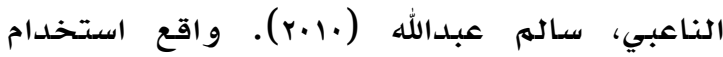

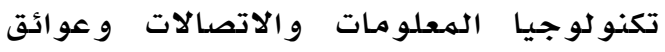

الاستخدام لدى عينة من معلمي و معلمات

مدارس المنطقة الداخلية بسلطنة عمان.

مجلة العلوم التربوية والنفسية، ل|(r)،

$. Y \cdot 1-1 V T$

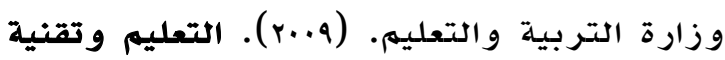

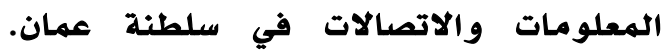

سلطنة عمان: وزارة التربية والتعليه.

وزارة التربية والتعليم (11) البم). الكتاب السنوي

للإحصاءات التعليمية. سلطنة عمان: وزارة

$$
\text { التر بية و التعليم. }
$$

وزارة التربية والتعليم (r/r). الكتاب السنوي

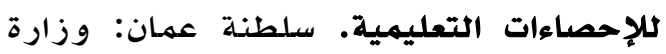

$$
\text { التر بية و التعليم. }
$$

$$
\text { اللهيبي، محمد مبارك (0.... ). الإنتر نت }
$$

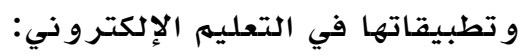

استعر اض لتجربة عملية. مجلة عالم الكتب،

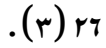

Effect of training. Theory $\mathcal{E}$ Research in Social Education, 34(1), 124-141.

EI-Hindi, A. (1998). Beyond classroom boundaries: Constructivist teaching with the Internet. The Reading Teacher, 51 (8), 694-700.

Friedman, A. M. (2006). World history teachers' use of digital primary sources: The

Gulbahar, Y. \& Guven, I. (2008). A Survey on ICT Usage and the perceptions studies teachers in Turkey. Educational Technology E Society, 11 (3), 37-51.

Integration in Jordanian school as perceived by in-service teachers. Jordan Journal of Educational Sciences 2 (4), 281-292.

Khazaleh, T. \& Jawarneh, T. (2006). Barriers to effective information technology
العتيبي، نايف (†..r). معيقات التعلم الإلكتروني

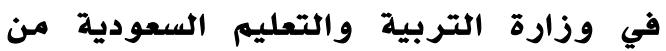

وجهة نظر القادة التربويين. رسالة

دكتور اه غير منشورة، جامعة مؤتة، الكرك،

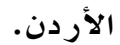

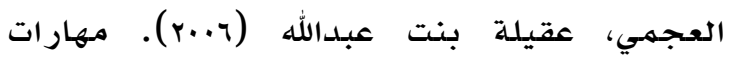
الحاسب الآلي لدى معلمي المرحلة الثانوية و الحلقة الثانية بسلطنة عمان و اتجاهاتهم لهاني

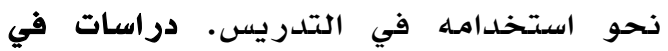
المناهج وطرق التدريس، III، IV -..1.

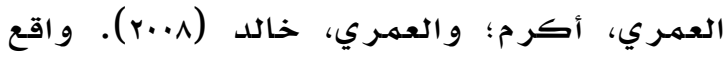

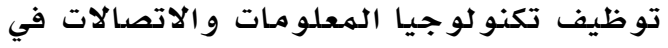

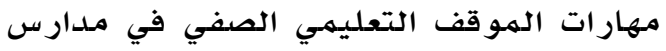
الصفوف الثلاثة الأولى في محافظة إربد من وجهة نظر المعلمين. مجلة جامعة الدابل تشرين للبحوث و والدراسات العلمية،•r(1)،

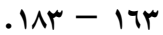

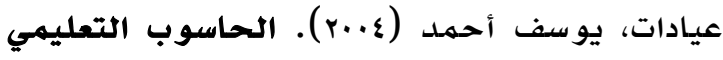

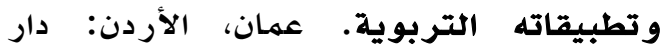
المسيرة للنشر و التوزيع و الطباعة.

الفار، زياد يوسف (11) (1). مدى فاعلية استخدام

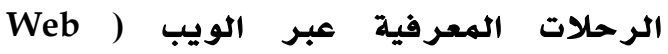

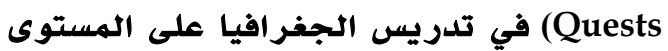

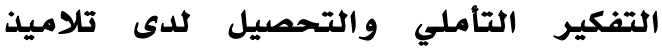
الصف الثامن الأساسي. رسالة ماجستير غير منشورة، جامعة الأزهر، غزة، فلسطين. القرشي، وائل بن سالم (r...v). واقع استخدام

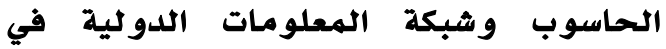

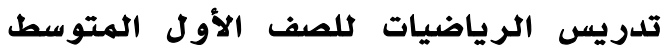

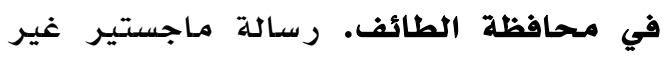
منشورة، جامعة أم القرى، الرياض، المملكة

$$
\text { العر بية السعودية. }
$$

الكناني، طواشي بن يوسف (r/.r). واقع استخدام

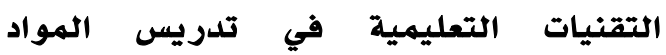
الاجتماعية بالمرحلة المتوسطة و ومعوقاته بمدارس البنين في محافظة القنفذة. رسالة ماجستير غير منشورة، جامعة أم القرى، المافين الرياض، المملكة العربية السعودية. 
Rice, M., Margaret, L. \& Wilson, E.(1999). How technology aids constructivism in the social studies classroom, The Social Studies, 90 (1), 28-33.

Thomas, J., Scott, M., \& Sullivan, O.(2000). The Internet and information literacy: taking the first step toward technology education in the social studies. The Social Studies, 91 (3), 121-126.

Toriskie, J. (1999). The effect of internet usage on student achievement and student attitudes. Ph.D. thesis, Loyola University Chicago, Illinois: United States

Trevor, O. (2000). Learning with technology. English Journal Urbana, 90 (2), 4-32.

VanFossen, P. (2001). Degree of Internet/www use and barriers to use among secondary social studies teachers. International Journal of Instructional Media, 28 (1), 57-74. 